\title{
Rossby Waves and Eddies Observed at a Temperature Mooring in Northern South China Sea*
}

\author{
Y.-C. LIN \\ National Central University, Jhongli City, Taiwan \\ L.-Y. OEY \\ National Central University, Jhongli City, Taiwan, and Princeton University, Princeton, New Jersey \\ J. WANG AND K.-K. LIU ${ }^{+}$ \\ National Central University, Jhongli City, Taiwan
}

(Manuscript received 19 May 2015, in final form 14 November 2015)

\begin{abstract}
Annual Rossby waves in northern South China Sea had previously been studied using altimetry and model data; however, how they connect to subsurface temperature fluctuations has not been examined. This study analyzed a 22 -month, surface to $-500-\mathrm{m}$ temperature time series at $18.3^{\circ} \mathrm{N}, 115.5^{\circ} \mathrm{E}$, together with satellite and other data, to show the arrivals near $z \approx-300 \mathrm{~m}$ and deeper cool (warm) Rossby waves after their generation near the Luzon Strait in winter (summer). Temperature fluctuations with time scales of a few weeks, and with maximum anomalies near $z \approx-100 \mathrm{~m}$, were also found embedded in the smooth Rossby waves and caused by propagating eddies. Eddy fluctuations and propagation past the mooring were of two types: southwestward from southwestern Taiwan, triggered by Kuroshio intrusion that produced anticyclone-cyclone pairs in late fall and winter, and eddies propagating westward from Luzon forced by annual anomalies of wind stress curl and Kuroshio path in the Luzon Strait
\end{abstract}

\section{Introduction}

Wyrtki (1961) described the upper-layer (here defined as being from the surface to $\sim 500 \mathrm{~m}$ below) circulation in South China Sea (SCS; Fig. 1) as being cyclonic in winter and anticyclonic in summer. In the northern SCS (NSCS; north of $\sim 16^{\circ} \mathrm{N}$; this study region), Fang et al. (1998) discussed that the circulation was driven by monsoon winds and Kuroshio intrusion and noted the existence of a cyclone northwest of Luzon in winter. This so-called

\footnotetext{
+ Deceased.
}

* Supplemental information related to this paper is available at the Journals Online website: http://dx.doi.org/10.1175/JPO-D-15-0094.s1.

Corresponding author address: L.-Y. Oey, Atmospheric and Oceanic Sciences Program, 300 Forrestal Rd., 114 Sayre Hall, Princeton University, Princeton, NJ 08540.

E-mail: lyooey@gmail.com
West Luzon Eddy (with a diameter of $\sim 300 \mathrm{~km}$ ) was confirmed using hydrographic observations by Qu (2000), who attributed local Ekman pumping as its main forcing. Liu et al. (2001) used altimetry data and analytical and numerical [the Princeton Ocean Model (POM)] models to analyze sea surface height (SSH) variability and showed that annual (i.e., seasonal) Rossby waves were forced by (the anomalies of) the wind stress curl (WSC) of seasonal monsoons. They argued that because of the small domain and fast Rossby wave speeds $C_{R}$ at relatively low latitudes, SCS is in quasi-steady Sverdrup balance at the annual period but noted that the models performed poorly in NSCS especially with a closed Luzon Strait. Yang and Liu (2003) also used altimetry data and POM and showed the spinup of the West Luzon Eddy in winter by WSC and west-northwestward propagation of forced Rossby waves originating from Luzon; the effects of Kuroshio on the eddy were found to be minor. These seasonal variabilities of circulation in SCS have been reproduced in models (e.g., Xue et al. 2004; Gan et al. 2006). Xu and Oey (2015) revisited the forced Rossby wave problem 
(a)

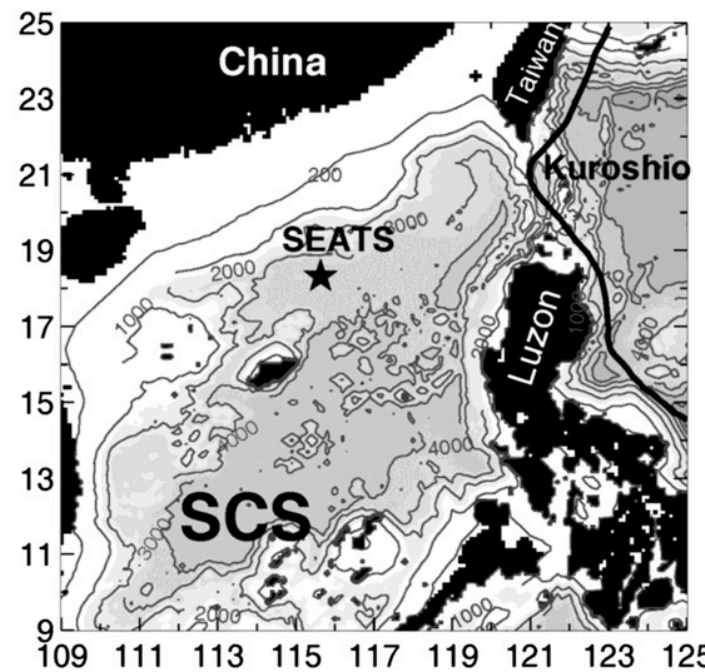

(b)

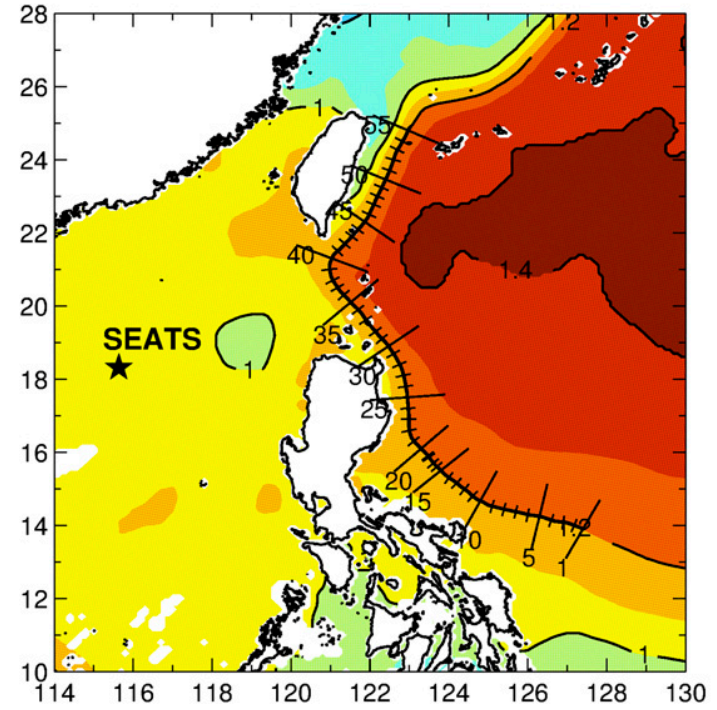

FIG. 1. (a) South China Sea topography and SEATS location $\left(18.3^{\circ} \mathrm{N}, 115.5^{\circ} \mathrm{E}\right)$. Black line east of Luzon is the Kuroshio. (b) Maps of Absolute Dynamic Topography (MADT; color and contours) showing the mean Kuroshio path $(\mathrm{KP}$; $\mathrm{SSH}=1.2 \mathrm{~m})$ and the sections along it. Sections 29-41, east of the Luzon Strait, are used for analyses.

focusing on the NSCS; they showed that local Ekman pumping was the leading empirical orthogonal function (EOF) mode of altimetry SSH anomaly (SSHA) and that the effect of Kuroshio intrusion (the Luzon Strait transport) was to reduce the analytical prediction of twice the Rossby wave speed due to the WSC forcing to better agree with the observed wave speed estimated from altimetry data.

Besides Rossby waves, mesoscale eddies were also observed. The distinction between linear waves and nonlinear eddies should be noted. Linear Rossby waves assume that the fluid's speed is much weaker than the wave phase speed (e.g., Gill 1982). On the other hand, nonlinear eddies tend to trap fluid parcels within them, and the parcel's rotational speed is larger than the translational speed of the eddy (Samelson 1992; Chelton et al. 2011). Chu et al. (1998) analyzed airborne expendable bathythermograph (AXBT) data in May of 1995 (i.e., a "snapshot" instead of seasonal averages) and showed that eddies were ubiquitous in SCS; the observation indicated that eddies were embedded in the smoother large-scale field of Rossby waves. Model results support the idea that the West Luzon Eddy in winter is generated by WSC (e.g., Metzger 2003; Gan et al. 2006). On the other hand, eddies were also observed southwest of Taiwan. Caruso et al. (2006) analyzed in situ observations, satellite SSHA, and sea surface temperature (SST) and showed that Kuroshio tended to intrude to the southwest of Taiwan in winter and shed eddies that propagated southwestward (see also Liang et al. 2008). Using altimetry data, Wang et al. (2008) found that cyclones and anticyclones tended to cluster northwest of Luzon and southwest of Taiwan, respectively. Since the winter monsoon wind is most intense in the middle of the Luzon Strait, the eddy distribution mirrored the pattern of WSC, and the authors suggested that eddies could be spun up by WSC. On the other hand, Nan et al. (2011) noted that the eddy occurrence estimated from altimetry SSHA was only weakly correlated with WSC and argued instead that Kuroshio intrusion would be more effective in generating eddies in NSCS. Instead of SSHA, Li et al. (2011) used drifters and were able to identify small (radius $<10 \mathrm{~km}$ ) as well as medium to large $(>60 \mathrm{~km})$ eddies. Medium to large eddies tended to cluster west-northwest of Luzon; cyclones slightly outnumbered anticyclones, and more were found in winter. Southwest of Taiwan, eddies were smaller, and anticyclones slightly outnumbered cyclones. Chen et al. (2010) examined the vertical structure of a warm eddy northwest of Luzon using an Argo float that was trapped in the eddy and followed it as the eddy moved westward; the maximum temperature anomaly was found near $z \approx-100 \mathrm{~m}$ (see also Chen et al. 2011). Hu et al. (2012) found from shipboard ADCPs an example of an anticyclone with a radius of $\approx 75 \mathrm{~km}$ that had penetrated through the Kuroshio into NSCS in winter. Zhang et al. (2013) analyzed currents and temperatures measured in the upper $470 \mathrm{~m}$ from ADCPs, thermometers, and CTDs moored for 12 months southwest of Taiwan and found southwestward-propagating eddies of both signs with radii $\approx 75 \mathrm{~km}$; the maximum temperature anomaly was found near $z \approx-150 \mathrm{~m}$.

In summary, previous studies used altimetry SSHA data and model results to describe annual Rossby waves in NSCS. However, the connection of subsurface temperature fluctuations to the passage of Rossby waves detected in SSHA remains elusive; the reason is because of a lack of continuous subsurface measurement of sufficiently long period. Mesoscale eddy variability in 
NSCS was also previously examined using altimetry SSHA, in situ, drifter, and Argo observations as described above. However, how the corresponding subsurface temperature fluctuations can be separated from the slower-varying Rossby wave was not addressed. Moreover, while the role of WSC forcing has previously been discussed, how eddy and Rossby wave variabilities are related to forcing by Kuroshio path fluctuations in the Luzon Strait has not been described. In this study, a 22-month (October 2000 to August 2002) temperature time series from the surface to $z=-500 \mathrm{~m}$ at the Southeast Asian Time Series Study (SEATS; Wong et al. 2007) station $\left(18.3^{\circ} \mathrm{N}, 115.5^{\circ} \mathrm{E}\right.$; Fig. 1$)$ is analyzed together with other data to relate the observed temperature fluctuations to Rossby waves and eddies. The data are to date the only freely available observations that are longer than the minimum of $1 \mathrm{yr}$ necessary for the analysis of annual Rossby waves. The SEATS mooring is centrally located in NSCS, due west of Luzon and southwest of Taiwan, and is therefore ideally in the corridor of Rossby waves and eddies. From the nearly 2 yr of observation, we are able to detect a baroclinic Rossby waves as its energy reaches the deeper part of the mooring, below $z \approx-300 \mathrm{~m}$, from Luzon. The signals of mesoscale eddies, with large temperature fluctuations near $z \approx-100 \mathrm{~m}$, are concurrently identified and shown to propagate in the smoother field of large-scale Rossby wave. Section 2 presents the data and methods. Section 3 describes the results and analyses. Section 4 is discussion, and section 5 concludes the paper.

\section{Data and method}

The SEATS temperature measurements were taken at $z=-1,-25,-50,-75,-100,-125,-150,-200$, $-250,-300$, and $-500 \mathrm{~m}$; full details of the observations are given in Wong et al. (2007). The SEATS mooring was located in the deep basin of the SCS away from the continental shelf break of NSCS in a water depth of $\sim 3300 \mathrm{~m}$. Missing data were filled by linear interpolation, and the data were then low-passed with a 40-h Butterworth filter to remove tides and other highfrequency fluctuations and organized into daily time series (Fig. 2a).

The World Ocean Atlas (WOA) data were downloaded online (from http://www.nodc.noaa.gov/OC5/ WOA05/pr_woa05.html; WOA05; Antonov et al. 2006; Locarnini et al. 2006). The wind data are from the crosscalibrated multiplatform (CCMP; Atlas et al. 2009) analysis product, available from 2 June 1987 to $31 \mathrm{De}-$ cember 2011. The data are 6-hourly gridded at $14^{\circ} \times 1 / 4^{\circ}$ resolution and are also low-pass filtered using the $40-\mathrm{h}$ Butterworth filter and organized into daily data. Weekly gridded sea surface height anomaly $\left(\mathrm{SSHA}=\eta^{\prime}\right)$ data from Archiving, Validation, and Interpretation of Satellite Oceanographic Data (AVISO) at $1 / 4^{\circ} \times 1 / 4^{\circ}$ resolution, from 1993 to 2013, were downloaded (AVISO 2013; http://www.aviso.oceanobs.com/). The mean dynamic topography (MDT; Rio et al. 2011) was also downloaded from the AVISO website and combined with SSHA to form a total sea surface height $(\mathrm{SSH}=\eta)$ time series. We used SSHA to analyze eddies and SSH and used the corresponding geostrophic currents to determine a time-dependent Kuroshio path (KP) in the Luzon Strait. The KP was determined from SSH following the method of Wang and Oey (2014). Along the mean Kuroshio path, local coordinates $(n, s)$ corresponding to axes across and along the local direction of the path were defined; positive $n$ points to the right of $\mathrm{KP}$, generally toward the open Pacific basin, while positive $s$ is generally poleward along KP. We then defined 55 cross-jet sections at equal along-jet intervals, $\Delta s=$ $10 \mathrm{~km}$, from $14^{\circ} \mathrm{N}$ approximately where the North Equatorial Current bifurcates to the northeast of Taiwan, where the Kuroshio enters the East China Sea (Fig. 1b); in NSCS, the effects of KP fluctuations are felt through stations $29-41$ in the Luzon Strait. The timedependent Kuroshio position $[\operatorname{KP}(s, t)]$ was then calculated at each cross section as the $n$ coordinate of the center of the cubed geostrophic velocity computed from AVISO [see Wang and Oey (2014) for details]. The KP has the same sign as $n$ : that is, positive (negative) to the right (left) of the mean Kuroshio path.

The various data were linearly interpolated to daily values to coincide with the SEATS daily data during the latter's period. In some cases, data were running averaged, as will be made clear in each case, and annual climatology was also removed. Quoted correlations are above the $95 \%$ significance level Sig (i.e., the $p$ value $\leq$ $0.05)$, calculated as $1-(1-0.95)^{2 /(F-1)}$, where $F=N / \tau_{N}$ is the number of degrees of freedom, $N$ is the length of the time series, and $\tau_{N}$ is the dot product of the autocovariances of the two time series. The notation $\operatorname{Corr}(A, B$, lags $)$ is used to denote maximum lagged correlation coefficient between $A$ and $B$ with lags in units that will be clearly stated, and the value is positive (negative) if $A$ leads (lags) $B$; for simplicity, the notation $\operatorname{Corr}(A, B)$ is used if lags $=0$.

EOF (Kutzbach 1967) and singular value decomposition (SVD; Bretherton et al. 1992) analyses are used to help interpret the SEATS and other observations. In addition to Kutzbach (1967) and Bretherton et al. (1992), another excellent description of EOF is contained in Kundu et al. (1975) and that of SVD is in Venegas et al. (1997). As the SVD may be unfamiliar to some readers, a brief description is given here. The SVD method is applied to two fields, each of which can be in 


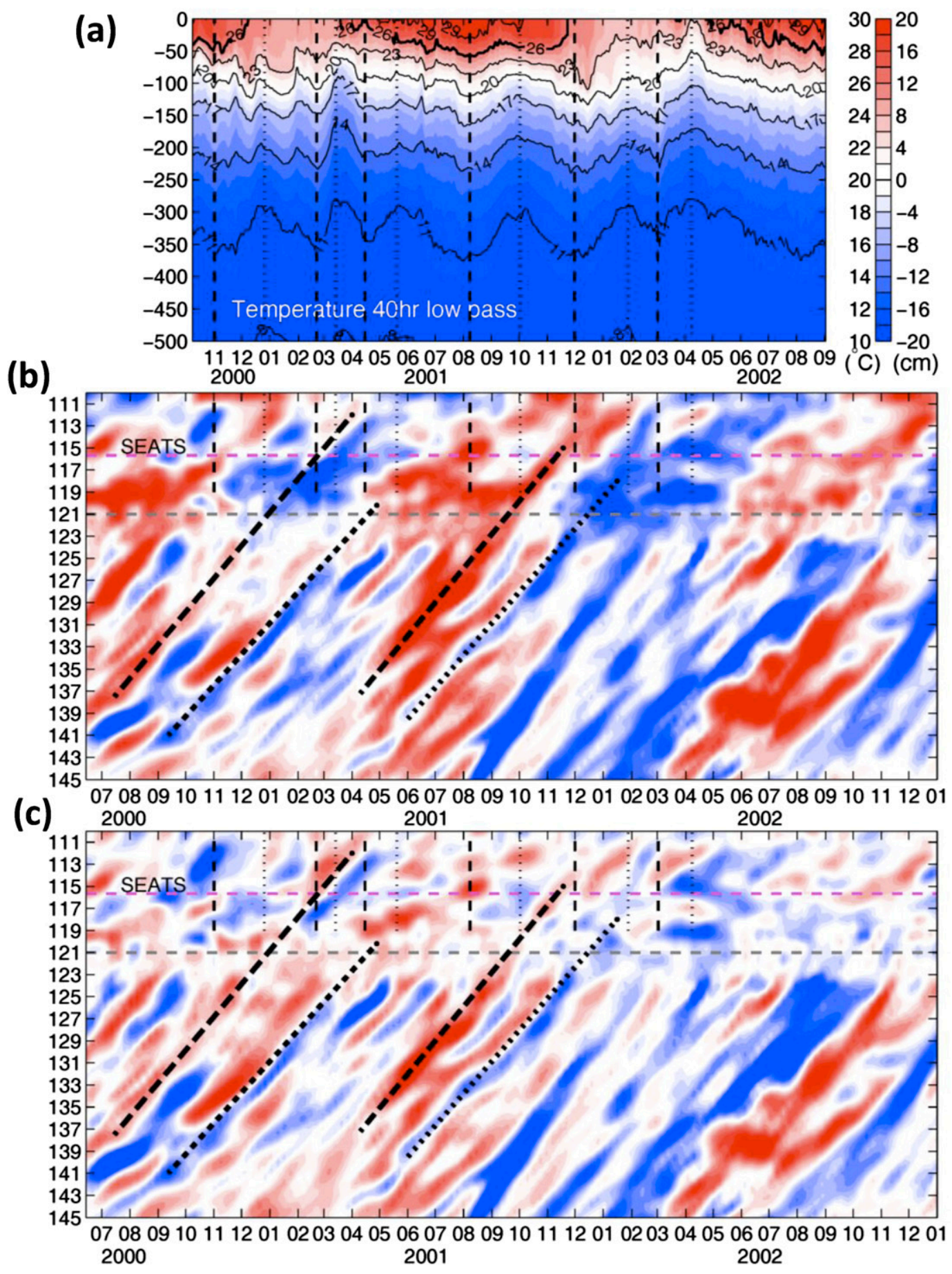

FIG. 2. (a) SEATS temperature from October 2000 to September 2002 and from the surface to $z=-500 \mathrm{~m}$. Hovmöller diagrams of (b) SSHA and (c) deseasoned SSHA at SEATS latitude $\left(18.3^{\circ} \mathrm{N}\right)$ from $110^{\circ}$ to $145^{\circ} \mathrm{E}$ for time period from 4 months before to 4 months after the SEATS period. Magenta and gray dashed lines indicate SEATS and Luzon Strait longitudes. Dashed (dotted) vertical lines indicate when higher (lower) SSHA appear at the SEATS location. Slanted dashed (dotted) lines indicate eddies that propagated into NSCS from the western Pacific Ocean, identified by Lu and Liu (2013). 
different spatial domains; the method then identifies those modes of behavior in which the variations of the two fields are coupled. For example, in the present study, one variable is $\eta$, which is a function of $(x, y)$, while the other variable is SEATS $T$, which is a function of $z$. The two fields span the same time period that in the case of $\eta$ and SEATS $T$ is the shorter of the two, that is, the SEATS period from October 2000 to August 2002. The temporal cross-covariance matrix between the two fields, which in general is nonsquare, is constructed. The method then yields two spatially uncorrelated sets of singular vectors: the spatial patterns (sp), which are $x-y$ maps in the case of $\eta$, and vertical $z$ profiles in the case of $T$. These sp are analogous to the EOF eigenvectors (EV), but now each variable has its own set of sp. Each pair of singular vectors describes a fraction of the square covariance between the two variables. The first pair explains the largest fraction, while the next pair describes the maximum fraction of the square covariance that is unexplained by the previous pair, and so on. Associated with the $k$ th singular vector pair is a $k$ th singular value (analogous to the EOF eigenvalue) whose square is then proportional to the square covariance fraction (SCF) accounted for by that $k$ th pair. To describe how the spatial patterns evolve in time, each of the $k$ th pair of sp is projected onto its own original data field, $\eta$ and $T$ in the present example, yielding the $k$ th pair of expansion coefficients (ec) [analogous to the EOF principal component (PC)], the ec time series. Finally, the strength of coupling between the $k$ th sp pair is measured by the size of the correlation coefficient $r$ of their corresponding $k$ th ec pair. In addition to the above cited, discussions and applications of the method in climate and oceanographic literature can be found in Wallace et al. (1992), von Storch and Navarra (1995), Newman and Sardeshmukh (1995), Chang et al. (1997), Venegas et al. (1996), Wang et al. (2003), Chang and Oey (2013), and Oey et al. (2015).

\section{Results}

\section{a. Time series of temperature and SSHA}

Figure 2a shows the SEATS temperature $T$ as a function of depth and time. Annual variation is seen from the surface to $z \approx-50 \mathrm{~m}$, within which $T$ is warmer than $\sim 26^{\circ} \mathrm{C}$ from April to November (2001), and more homogeneous and cooler waters prevailed from December to March. However, annual variation is also present at deep levels. There, isotherms additionally show undulations of shorter periods of a few weeks to $\sim 2$ months. Both annual and short-period signals extend to depths of at least $350 \mathrm{~m}$.

Before discussing detailed analyses in the following sections, we here show how the temperature undulations observed at the SEATS mooring are qualitatively related to SSHA. Figures $2 \mathrm{~b}$ and $2 \mathrm{c}$ show Hovmöller plots along the SEATS latitude $\left(18.3^{\circ} \mathrm{N}\right)$ from $110^{\circ}$ to $145^{\circ} \mathrm{E}$ using SSHA (Fig. 2b) and the deseasoned, highpass filtered SSHA $\eta-\eta_{a}$ (Fig. 2c), where $\eta_{a}$ is the annual climatology of SSHA computed by averaging 21-yr SSHA data from 1993 to 2013. Note that the SSHA includes both annual Rossby waves and eddies, whereas the high-pass filtered $\eta-\eta_{a}$ consists primarily of eddies. Both plots show nearly identical features in the open Pacific east of the Luzon Strait, $\sim 121^{\circ} \mathrm{E}$; there, high and low SSHAs can be seen to propagate westward. Such westward-propagating features in the open Pacific have previously been described by Chelton et al. (2011), who regarded them as nonlinear eddies. By comparing the two plots (Figs. 2b,c), it is clear that in the open Pacific eddy signals dominate, but near the Luzon Strait and in NSCS, eddy signals are embedded in a background of annual variation. The SSHA is generally positive from May to September and negative from October to April. Sheu et al. (2010) showed that strong PV jump across the Kuroshio tends to block eddies, and Lu and Liu (2013) found that only relatively few eddies could penetrate through the Luzon Strait into NSCS. Four of the eddies identified by Lu and Liu (2013) using a feature-tracking scheme are indicated in Figs. $2 b$ and $2 c$ (slanted lines). From Fig. 2c, one may differentiate at the SEATS location the two warm features identified by Lu and Liu (2013) as eddies that propagated from the open Pacific (February and November 2001) and other eddies that were locally generated within the NSCS. By comparing with Fig. 2a, there are visual correlations between rising (falling) isotherms and negative (positive) SSHAs at the SEATS location, suggestive of the arrival of cold (warm) eddies.

In the following, we quantify and explain the processes that connect SEATS temperature and SSHA. We separate temperature fluctuations due to eddies and Rossby waves and quantitatively relate each of them to the SSHA fluctuations using the SVD. Finally, the connection with KP is identified.

\section{b. Temperature fluctuations at annual and eddy time scales}

Figure 3 shows EOF EV and PCs for modes $1-2$ of the SEATS temperature. Mode 1 accounts for $64 \%$ of the total variance (Fig. 3a). The $\mathrm{EV}_{1}$ is trapped near the surface $(\sim 50 \mathrm{~m})$. The $\mathrm{PC}_{1}$ shows an annual variation interspersed with shorter-period fluctuations of 12 months (Fig. 3c). Mode 2 accounts for $29 \%$ of the total variance (Fig. 3b). The $\mathrm{PC}_{2}$ displays energetic fluctuations at short periods of 1-2 months (Fig. 3d). However, an annual signal remains, such that it is generally cooler from December to March and warmer from April to November. This annual signal is significantly correlated 
(a)

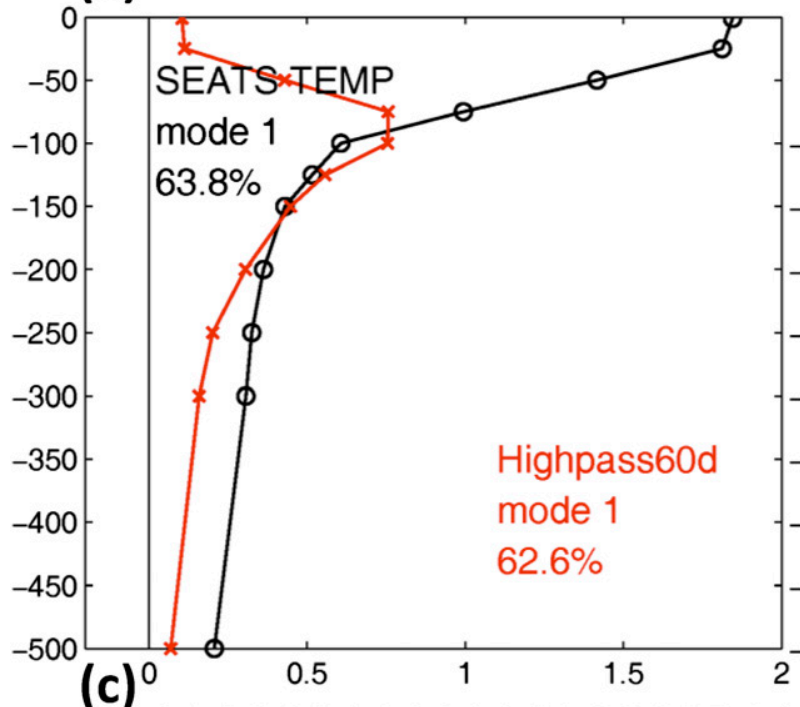

(b)

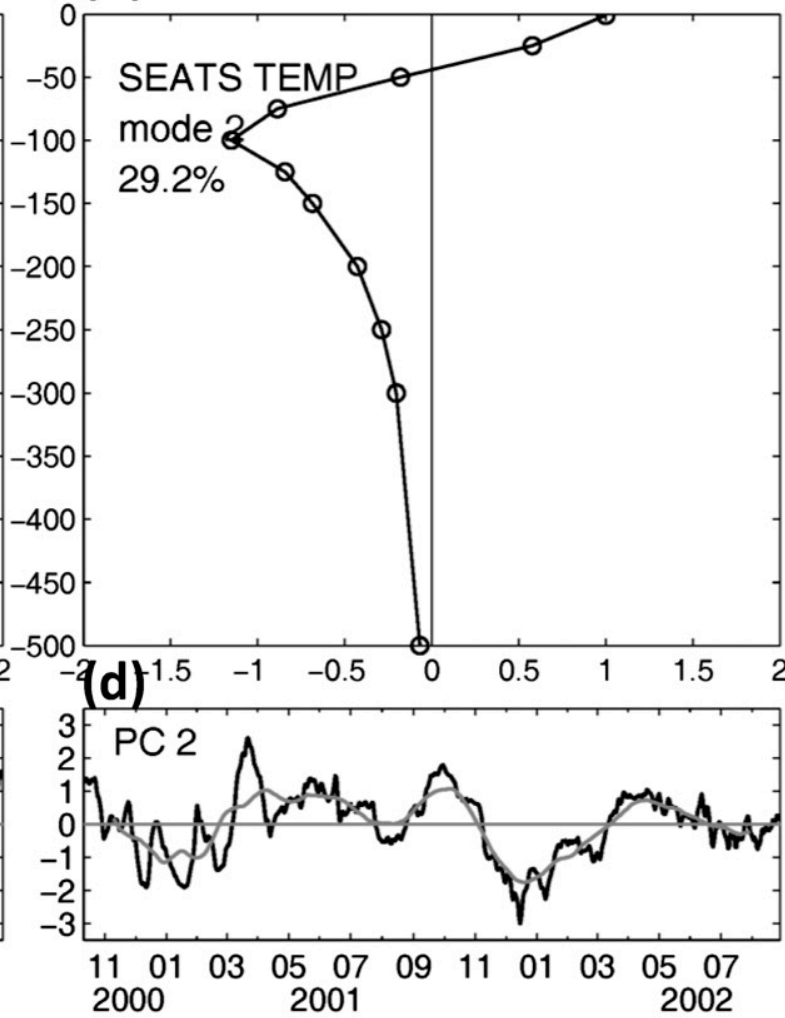

(e)
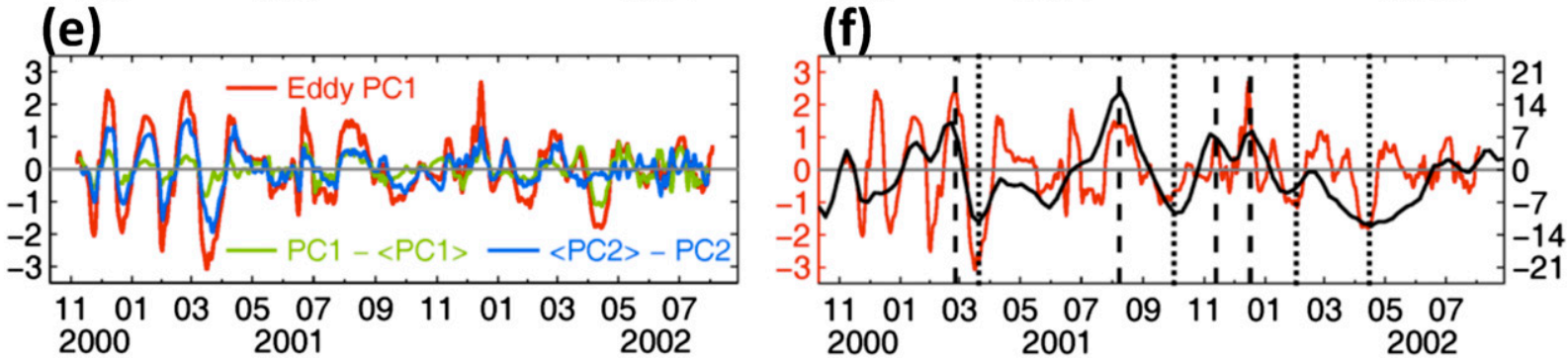

FIG. 3. EOF modes (a),(c) 1 and (b),(d) 2 for SEATS $T$ profile. (a) and (b) are EV (black lines; abscissa is in ${ }^{\circ} \mathrm{C}$ and ordinate is $z$ in m; circle and cross symbols indicate the SEATS levels) and (c) and (d) are PCs (black lines). Gray lines in the PC plots are 60-day running means $(\langle\rangle$.$) . Red lines in (a) and (c) are the eddy EOF mode 1$ of $T-\langle T\rangle$. (e) Red line is the same as the red line of eddy $\mathrm{PC}_{1}$ plot in (c); green is black minus grey from Fig. 3c, and blue is similarly the black minus grey from Fig. 3d but with sign reversed. (f) Black line is deseasoned SSHA at SEATS (from Fig. 2c; in cm), and red is the same as the red line of eddy $\mathrm{PC}_{1}$ plot in (c). Dashed (dotted) vertical lines indicate warm (cold) eddy $\mathrm{PC}_{1}$ and higher (lower) SSHA at SEATS.

with $\mathrm{PC}_{1}$ and $\operatorname{Corr}\left(\left\langle\mathrm{PC}_{2}\right\rangle,\left\langle\mathrm{PC}_{1}\right\rangle, 66\right.$ days $)=0.84$, where $\langle$. denotes the 60-day running mean (gray lines), with $\mathrm{PC}_{2}$ leading. The $\mathrm{EV}_{2}$ is positive at the surface, is of opposite sign at $z \approx-100 \mathrm{~m}$ with slightly larger magnitude than the surface, and becomes weak at deep depths. The strong subsurface signal (at $z \approx-100 \mathrm{~m}$ ) is reminiscent of the structure observed for eddies in the open Pacific by Roemmich and Gilson (2001, their Fig. 5), where the strong anomaly was located at $z \approx-150 \mathrm{~m}$. To confirm the eddy signal, we repeated the EOF analysis on the high-pass filtered time series:

$$
T_{\text {eddy }}=T-\langle T\rangle
$$

where $\langle$.$\rangle is a low-pass filter taken simply as the 60-day$ running mean. [The choice of 60 days was based on examining the Hilbert spectrum of $T^{\prime}$ using the Hilbert-Huang transform (HHT) method (Huang et al. 1998; Oey et al. 2008, 2009); however, the results are very similar when 40 and 90 days are used as the running means.] The resulting mode 1 now contains a strong eddy signal, shown as red lines in Figs. $3 \mathrm{a}$ and $3 c$, and the resulting eddy $\mathrm{EV}_{1}$ displays a subsurface 
maximum at $z \approx-100 \mathrm{~m}$ (Fig. 3a). The eddy $\mathrm{PC}_{1}$ (red line in Fig. 3c) is nearly identical to the sum of $\left(\mathrm{PC}_{1}-\left\langle\mathrm{PC}_{1}\right\rangle\right)$ and $\left(\left\langle\mathrm{PC}_{2}\right\rangle-\mathrm{PC}_{2}\right)$ (black minus grey curves in Figs. $3 \mathrm{c}$ and 3d, as shown in Fig. 3e. ${ }^{1}$ We can further compare eddy $\mathrm{PC}_{1}$ with deseasoned, high-pass filtered SSHA (Fig. 3f). Correspondence between high (low) SSHA and warm (cold) eddy $\mathrm{PC}_{1}$ can be seen during some periods. However, the eddy $\mathrm{PC}_{1}$ shows shorter-period temperature fluctuations that are not apparent in the AVISO data, probably because of the latter's inadequate temporal and spatial resolutions.

The EOF analysis above indicates that the SEATS measurements detected short-period eddy fluctuations $T_{\text {eddy }}$ embedded in a background of nearly annual fluctuation $T_{a}$. We therefore write

$$
T=T_{a}+T_{\text {eddy }}+\varepsilon,
$$

where $\varepsilon$ is a residual (e.g., interannual variability) that is assumed small in comparison to other contributions. Using (3.1), we then have

$$
\langle T\rangle=T_{a}+\varepsilon \approx T_{a} .
$$

The $T_{a}$ can be further decomposed into fluctuations $T_{\mathrm{SF}}$, purely due to local surface fluxes, and $T_{\mathrm{RW}}$, due to the annual Rossby wave:

$$
T_{a}=T_{\mathrm{SF}}+T_{\mathrm{RW}} .
$$

The $T_{\mathrm{SF}}$ is defined to have no horizontal variation and once surface fluxes are specified is physically driven in the water column by vertical mixing. The $T_{\mathrm{SF}}$ is estimated by running a one-dimensional $z$ time-dependent model using POM, forced at the surface by wind stress calculated from the 6-hourly CCMP wind data and by heat fluxes from the NCEP reanalysis data (see Mellor 2001; Sun et al. 2015), from 1988 to 2011. The $\sim 12$-yr (1988-2000) integration prior to the SEATS period ensured that a quasi-oscillatory solution has been reached before the SEATS period. The $T_{\mathrm{SF}}$ during the SEATS period is shown in Fig. SM-1 of the supplemental information, which shows that the influence of $T_{\mathrm{SF}}$ is primarily confined in the surface mixed layer of depth $\sim 50 \mathrm{~m}$. The variation is not purely annual as the surface forcing itself changes from year to year; nonetheless, the effects during the relatively short SEATS period are small.

\footnotetext{
${ }^{1}$ The sign of $\mathrm{PC}_{2}$ is reversed to account for the different signs near $z=-100 \mathrm{~m}$ between $\mathrm{EV}_{2}$ in Fig. $3 \mathrm{~b}$ and eddy $\mathrm{EV}_{1}$ in Fig. $3 \mathrm{a}$ (red line).
}

\section{c. Temperature fluctuations due to annual Rossby wave $T_{R W}$}

The strong annual SSHA in northern South China Sea (Fig. 2b) contains annual Rossby wave forced by WSC and Luzon Strait transport (LZT). This can be seen by considering the following reduced-gravity model for forced baroclinic long waves:

$\partial \psi / \partial t-C_{R} \partial \psi / \partial x=-W_{e}, \quad-\infty<x \leq 0, \quad t \geq 0$.

Here, $\psi=\left(g^{\prime} H_{o} / f\right) h$ is the streamfunction of the upper layer $h$ (with mean depth $H_{o}$ ) that overlies an infinitely deep, motionless lower layer; $x$ is the zonal coordinate; $x=0$ at the eastern SCS or the Luzon Strait; $t$ is the time; $C_{R}$ is the Rossby wave speed; $W_{e}=\left(g^{\prime} H_{o} / f\right) \nabla \times \tau^{o} / f$ is the forcing term due to Ekman pumping; ${ }^{2} g^{\prime}$ is the reduced gravity; $f$ is the Coriolis frequency; and $\tau^{o}$ is the wind stress divided by water density. The model (3.5) was previously used for SCS by various authors (e.g., Liu et al. 2001; Xu and Oey 2015). The initial and boundary conditions and $W_{e}$ are specified as

$$
\begin{aligned}
\psi(x, t=0) & =\psi_{o}(x), \quad \psi(x=0, t)=A_{E} \cos (\omega t), \\
W_{e} & =A_{\tau} \cos (\omega t),
\end{aligned}
$$

where $\omega=2 \times 10^{-7} \mathrm{~s}^{-1}(2 \pi / 1 \mathrm{yr})$ is the annual frequency, $A_{\tau}$ is the amplitude of the Ekman pumping streamfunction in units of cubic meters per squared second, and $A_{E}$ is the amplitude of $\psi$ in units of cubic meters per second at the eastern boundary. In the case of the Luzon Strait, $A_{E}$ is the amplitude of transport (LST) variation through the strait. If the eastern boundary is closed, then $A_{E}=0$. We take $t=0$ to be 1 January (i.e., winter) when both the WSC and inflow transport are at maximum. A solution of (3.5) and (3.6) is (see $\mathrm{Xu}$ and Oey 2015)

$$
\begin{aligned}
\psi(x, t)= & -\left(2 A_{\tau} / \omega\right) \sin (k x / 2) \cos (k x / 2-\omega t) \\
& +A_{E} \cos (k x-\omega t),
\end{aligned}
$$

where $k$ satisfies the long Rossby wave dispersion relation

$$
\omega=-C_{R} k \text {. }
$$

Equation (3.7) describes westward propagation of annual Rossby waves forced by a combination of WSC (first term on rhs) and LZT (second term). Xu and Oey (2015) show that in NSCS, the WSC accounts for approximately $60 \%$ of the amplitude and the LZT accounts for $40 \%$. The WSC generates long, nondispersive

\footnotetext{
${ }^{2}$ Effect of surface cooling can also be included.
} 


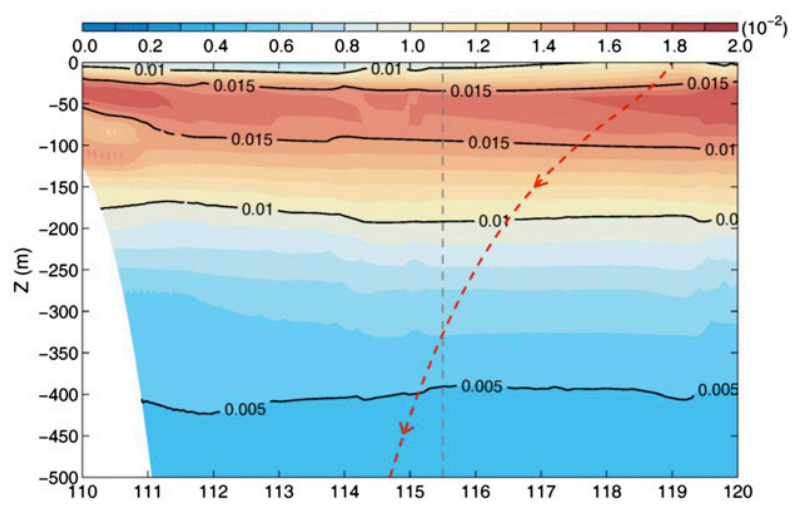

FIG. 4. Zonal section of $N\left(\mathrm{~s}^{-1}\right)$ at $18.3^{\circ} \mathrm{N}$ from annual-mean WOA passing the SEATS location (vertical dashed line) and annual Rossby wave ray (red dashed line) emanating from the surface west of Luzon.

Rossby waves with phase (group) velocity $=-2 C_{R}$ westward (White 1977), where $C_{R} \approx 0.06 \mathrm{~m} \mathrm{~s}^{-1}$ in NSCS. The LZT, on the other hand, produced Rossby waves propagating at $-C_{R}$. Xu and Oey (2015) estimated from altimetry data that the observed westward speed was $C_{R \text { obs }}=0.1 \pm 0.01 \mathrm{~m} \mathrm{~s}^{-1}$ along $18^{\circ} \mathrm{N}$, consistent with the theoretical expectation that the speed was slower than $2 C_{R}$ but faster than $C_{R}$. Starting near the surface in the east, as a Rossby wave propagates westward, temperature fluctuations occur at increasingly deeper levels; in other words, the wave energy propagates westward and downward (Kessler and McCreary 1993; Ramos et al. 2008). The slope of the ray is derived from theory (see standard textbooks; e.g., Gill 1982) and is given by

$$
d z / d x=C_{g z} / C_{g x}=2 \omega f^{2} /(\beta c N),
$$

which shows that the wave dips downward as it propagates westward. Here, $\left(C_{g x}, C_{g z}\right)$ is the group velocity in the $x-z$ plane, $N$ is buoyancy frequency $\left(\approx 10^{-2} \mathrm{~s}^{-1}\right)$, and $c$ is mode- 1 baroclinic phase speed. Xu and Oey (2015) calculate using WOA that $c \approx 2.5 \mathrm{~m} \mathrm{~s}^{-1}$ in NSCS and show using the AVISO data that the center of dominant SSHA fluctuations is near $18^{\circ} \mathrm{N}, 119^{\circ} \mathrm{E}$ (see the EOF mode 1 of SSHA in Fig. SM-2b). Thus, taking $119^{\circ} \mathrm{E}$ as the initial $x$ location of the ray, and the fact that the observed $x$ component group speed $C_{R \text { obs }}\left(=C_{g x}\right)$ is faster, that is, $C_{R \text { obs }} / C_{R} \approx 1.67$, we can estimate from (3.9) the downward distance traveled by the wave as $\delta z \approx-315 \mathrm{~m}$ when the wave arrives at the SEATS mooring. Figure 4 plots the exact ray path computed from (3.9) and using the $N$ computed from the WOA shows $\delta z \approx-340 \mathrm{~m}$ is in good agreement with the simple estimate.

Thus, Rossby waves are excited near $119^{\circ} \mathrm{E}$ northwest of Luzon and propagate westward and downward following the energy ray. According to the theory, the wave packet containing the largest isothermal displacements is located near $z \approx-340 \mathrm{~m}$ when the wave arrives at the SEATS mooring. To demonstrate this using the SEATS data, we plot in Fig. 5a the 60-day running mean $\langle T\rangle$ at the SEATS mooring level $z=-300 \mathrm{~m}$, together with the sea surface height anomaly $\eta^{\prime}$ at $115.5^{\circ}$ (SEATS) and at $119^{\circ} \mathrm{E}$ (Luzon), at the same latitude as the SEATS mooring. At this $z$ level, the contribution from $T_{\mathrm{SF}}$ is weak, so that $T_{\mathrm{RW}} \approx\langle T\rangle$ from (3.3) and (3.4). The $\left.\eta^{\prime}\right|_{\text {SEATS }}$ agrees well with $\left.\langle T\rangle\right|_{z=-300 \mathrm{~m}}$ and is highly correlated: Corr $\left(\left.\eta^{\prime}\right|_{\text {SEATS }},\left.\langle T\rangle\right|_{z=-300 \mathrm{~m}}\right) \approx 0.93$. The $\left.\eta^{\prime}\right|_{\text {Luzon }}$ and $\left.\eta^{\prime}\right|_{\text {SEATS }}$ are correlated: $\operatorname{Corr}\left(\left.\eta^{\prime}\right|_{\text {Luzon }},\left.\eta^{\prime}\right|_{\text {SEATS }}, 35\right.$ days $) \approx 0.71$, giving an effective westward propagation speed of $0.115 \mathrm{~m} \mathrm{~s}^{-1}$ in agreement with the estimate of Xu and Oey (2015). Finally, the $\operatorname{Corr}\left(\left.\eta^{\prime}\right|_{\text {Luzon }},\left.\langle T\rangle\right|_{z=-300 \mathrm{~m}} ; 41\right.$ days $) \approx$ 0.62 . The vertical group velocity of Rossby waves $C_{g z}$ can be estimated (Gill 1982) to be $\approx-10^{-4} \mathrm{~m} \mathrm{~s}^{-1}$ so that in 35-41 days the downward distance traveled is approximately -302 to $-354 \mathrm{~m}$ consistent with the depth range below the surface where $\langle T\rangle$ was found to have the strongest fluctuations as we will show below (Fig. 6). Figure $5 \mathrm{~b}$ plots the correlations of $\left.\eta^{\prime}\right|_{\text {SEATS }}$ with both $\langle T\rangle$ and $\left\langle T-T_{\mathrm{SF}}\right\rangle$; as there were no measurements between $z=-300$ and $-500 \mathrm{~m}$, the plot suggests a maximum correlation somewhere between the two levels. This depth is close to the theoretical estimate obtained above: $\delta z \approx$ $-340 \mathrm{~m}$ at SEATS. These results suggest that the lowfrequency temperature fluctuations at the SEATS mooring indeed contained westward- and downward-propagating mode-1 Rossby waves triggered some 35-41 days earlier near the surface near Luzon. It is interesting that, although apparently unnoticed by the authors, the signature of such propagation of Rossby waves can be seen in the westward and downward tilting of the location of the maximum temperature anomaly in the model result of Yang and Liu (2003, their Fig. 7a).

\section{d. Connection between AVISO SSHA and SEATS $T_{R W}$ and $T_{e d d y}$}

SVD analyses are conducted to deduce covariability between sea surface height $\eta$ and $T$. The method sorts and ranks different covarying modes. In the present case, mode 1 contains annual Rossby waves, while eddy covariability is included in modes 2 and higher. However, it is physically more instructive to separately analyze the low- and highfrequency time series and therefore obtain two separate SVD analyses: a low-frequency one $\operatorname{SVD}(\eta,\langle T\rangle)$ and another, high-frequency one using the deseasoned, highpass filtered SSHA and $\mathrm{T}_{\text {eddy }}: \operatorname{SVD}\left(\eta-\eta_{a}, T_{\text {eddy }}\right)$.

\section{1) LOW-FREQUENCY ANALYSIS: $\operatorname{SVD}(\eta,\langle T\rangle)$}

In this case, the SCF of the first mode accounts for $70 \%$ of the total variance, and the first mode is well 

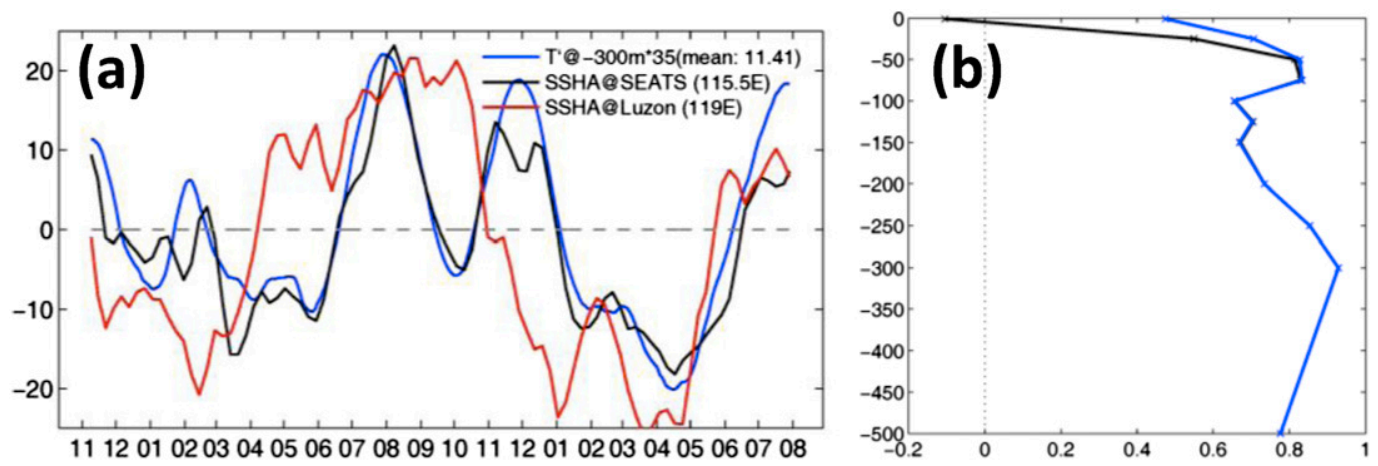

FIG. 5. (a) Time series of SEATS $\langle T\rangle_{60 \mathrm{~d}}$ anomaly (i.e., $T$ minus 22 -month mean $\left.=11.4^{\circ} \mathrm{C}\right)\left[\times 35 \approx \operatorname{Mean}(\partial T / \partial z)^{-1}\right.$ to give an estimate of isothermal displacement in $\mathrm{m}]$ at $z=-300 \mathrm{~m}$ (blue; ${ }^{\circ} \mathrm{C}$ ), SSHA at SEATS (black; cm), and SSHA at Luzon (red; cm). (b) Correlations of SSHA at SEATS with $\langle T(z, t)\rangle_{60 \mathrm{~d}}$ (blue) and $\left\langle T(z, t)-T_{\mathrm{SF}}\right\rangle_{60 \mathrm{~d}}$ (black); ordinate is $z$ in $\mathrm{m}$.

separated from the second mode that has SCF $=21 \%$. The strengths of covarying signals are measured by the correlation coefficients $r$ 's of their respective ec, which are high and significant for both modes. The ec 1 and 2 and spatial patterns (sp 1 and 2) of $\eta$ closely resemble the corresponding EOF PC1 and 2 and EV1 and 2 (see Figs. SM-2b,c). The ec1 and 2 (or PC1 and 2) are highly correlated $(r \sim 0.83)$ with ec ${ }_{2}\left(\mathrm{PC}_{2}\right)$, leading ec ${ }_{1}\left(\mathrm{PC}_{1}\right)$ by approximately 2 months, suggesting a propagating signal. The propagation can be clearly seen by plotting successive temporal maps of modes 1 and 2, as shown in Fig. 7. ${ }^{3}$ The ec ${ }_{1}(\eta)$ (Fig. 6a) shows lows in March of 2001 and January-March of 2002, which is 1-3 months after the peak WSC in December west of Luzon (Fig. SM-2a), while $\mathrm{ec}_{2}(\eta)$ (Fig. 6b) shows lows in Decembers of 2000 and 2001. Thus, $\mathrm{ec}_{1}(\eta)$ [or $\mathrm{PC}_{1}(\eta)$ ] lags WSC, while $\mathrm{ec}_{2}(\eta)$ [or $\left.\mathrm{PC}_{2}(\eta)\right]$ is in phase with WSC, which was also found by $\mathrm{Xu}$ and Oey (2015) using the longer AVISO data from 1993 to 2009 . As they pointed out, modes 1 and 2 are respectively contributions from the local variability $(\partial \psi / \partial t)$ and the planetary wave response (i.e., $\beta$ term $\left.C_{R} \partial \psi / \partial x\right)$ terms in the long Rossby wave equation (3.5). Together, modes 1 and 2 indicate westward propagation of annual Rossby waves with phase lines slanted from west-southwest to east-northeast (White 1977; Fig. 7). The covarying temperature structure $\mathrm{sp}_{1}(\langle T\rangle)$ (Fig. 6a) shows a surface intensification due to seasonal surface fluxes (i.e., due to $T_{\mathrm{SF}}$ ) and a deep intensification $(z \leq-300 \mathrm{~m})$. The deep mode together with the predominantly subsurface $\operatorname{sp}_{2}(\langle T\rangle)$ (Fig. 6b), which has the same negative sign as $\operatorname{sp}_{2}(\eta)$ at the SEATS location, are indicative of contribution from annual

\footnotetext{
${ }^{3}$ The propagation may also be analyzed using complex EOF (Merrifield and Guza 1990; Lin et al. 2007; Oey 2008), but for the present application the simpler EOFs are much more straightforward.
}

Rossby waves to vertical movements of isotherms, as described in the previous subsection. Therefore, as Rossby waves of high (low) SSHA propagated past the SEATS instrument, the latter detected a warm (cold) anomaly in the subsurface, in good agreement with the change in color of the star symbol in Fig. 7. From Figs. 6 and 3, annual Rossby waves account for approximately $60 \%-70 \%$ of the total variance; the remaining is dominated by shorter-period eddies that we analyze next.

\section{2) HIGH-FREQUENCY ANALYSIS: $\operatorname{SVD}\left(\eta-\eta_{\mathrm{A}}\right.$, $\left.T_{\text {EDDY}}\right)$}

In this case, mode- 1 SCF accounts for $52 \%$ of the total variance and is well separated from mode 2 , which has $18 \%$. The $r$ values of 0.59 (mode 1$)$ and 0.42 (mode 2 ) are weaker than those for the low-frequency SVD (Fig. 6), though they remain statistically significant at the $95 \%$ significance level. The correlation between the two modes $\mathrm{ec}_{1}$ and $\mathrm{ec}_{2}$ is very low $(<0.2)$, suggesting that, unlike the low-frequency ec of Fig. 6, the two SVD modes are not components of the same propagating pattern. The $\operatorname{sp}_{1}\left(\eta-\eta_{a}\right)$ shows a zonal pattern along $\sim 18^{\circ} \mathrm{N}$ from western Luzon through the SEATS station, and the pattern covaries best with a SEATS temperature fluctuating structure that is subsurface intensified, with a maximum anomaly at $z \approx-100 \mathrm{~m}$. Previous studies, both observational and modeling, have extensively documented that eddies west of $\mathrm{Lu}$ zon can be generated by WSC (Qu 2000; Metzger 2003; Xue et al. 2004; Gan et al. 2006; Wang et al. 2008, 2012). The mode- $1 \operatorname{SVD}\left(\eta-\eta_{a}, T_{\text {eddy }}\right)$ reflects the existence of these eddies during the SEATS period. A similar case of WSC-induced eddies in the Caribbean Sea was presented by Oey et al. (2003). From fall to winter, strong WSC west of Luzon produces Ekman upwelling $w_{e}=\nabla \times \tau^{o} / f \approx 4.4 \times 10^{-6} \mathrm{~m} \mathrm{~s}^{-1}\left[\right.$ using $\nabla \times \boldsymbol{\tau}^{o}=2 \times$ $10^{-10} \mathrm{~m} \mathrm{~s}^{-2}$; see Qu (2000), and $f \approx 4.5 \times 10^{-5} \mathrm{~s}^{-1}$ at 

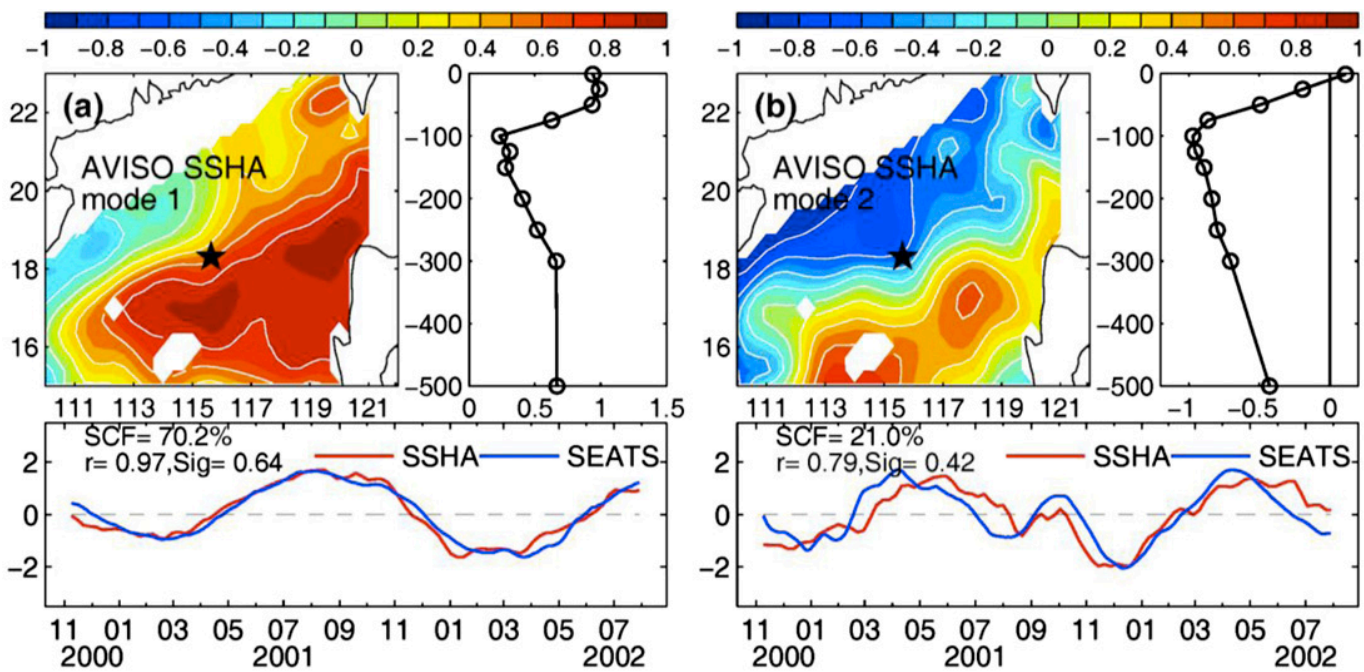

FIG. 6. SVD modes (a) 1 and (b) 2 of SSHA with $\langle T\rangle$. Upper subpanels show spatial patterns of SSHA and SEATS $T$, and the lower subpanels show the ec, both normalized by their respective standard deviations. The star symbol shows the SEATS location. SCF is the square covariance fraction, $r$ is the correlation coefficient between the ec, and Sig is the $95 \%$ significance level.

$\left.18^{\circ} \mathrm{N}\right]$. The pycnocline is uplifted by approximately $\sim 23 \mathrm{~m}$ in 60 days, and the radius of the cyclone $R_{e}$ is about $100 \mathrm{~km}$, the scale of the WSC. The $\beta$ effects become important in a time scale $t_{\beta}$ of about $2 R_{e} /\left(\beta R_{d}^{2}\right) \approx 35$ days, where the Rossby radius $R_{d} \approx 55 \mathrm{~km}$ in NSCS from Xu and Oey (2015, their Fig. $2 \mathrm{~b}$ ); $t_{\beta}$ is the time taken for long Rossby waves to traverse the eddy diameter (Matsuura and Yamagata 1982). Once formed, the eddy drifts westnorthwestward due to the combined action of Rossby wave propagation and self-advection as a result of the eddy's interaction with the wake of the Rossby wave (Matsuura and Yamagata 1982; Smith and O'Brien 1983). As will be discussed below, these estimates agree well with the AVISO SSHA data. ${ }^{4}$

Mode 2 (Fig. 8b) $\operatorname{sp}_{2}\left(\eta-\eta_{a}\right)$ shows a southwestward pattern from southwest of Taiwan through the SEATS mooring. The $\operatorname{sp}_{2}\left(T_{\text {eddy }}\right)$ shows that the corresponding covarying temperature fluctuations are strongest from the surface to $z \approx-100 \mathrm{~m}$. Caruso et al. (2006) and Zhang et al. (2013) have observed that southwest of Taiwan eddies are often produced as the Kuroshio meanders into NSCS through the northern half of the Luzon Strait. The mode- $2 \operatorname{SVD}\left(\eta-\eta_{a}, T_{\text {eddy }}\right)$ reflects the existence of these eddies during the SEATS period.

By compositing eddies along a ship track across the tropical-subtropical North Pacific Ocean, Roemmich

\footnotetext{
${ }^{4}$ Matsuura and Yamagata (1982) show that cyclone is dispersive. But the relatively small distance between SEATS and Luzon means that the eddy can propagate over that distance without excessively diminishing its amplitude.
}

and Gilson (2001) have shown that strong temperature anomalies tend to be near the eddy center and just below the thermocline, at $z=z_{\max } \approx-150 \mathrm{~m}$. Zhang et al. (2013) also obtained a similar $z_{\max } \approx-150 \mathrm{~m}$ for eddies southwest of Taiwan. On the other hand, Chen et al. (2010) found that the strong temperature anomaly was at a shallower depth of $z_{\max } \approx-100 \mathrm{~m}$ for a warm eddy propagating westward from northwest of Luzon, very nearly along the same latitude as the SEATS station $\left(18.3^{\circ} \mathrm{N}\right)$. Their value of $z_{\max } \approx-100 \mathrm{~m}$ agrees well with the mode- 1 temperature structure found in Fig. 8a, which shows a maximum anomaly at the same depth The difference $\delta z_{\max } \approx 50 \mathrm{~m}$ between the two sets of observations may in part be explained by the different thermocline depths. In Fig. SM-3, we superimpose the locations of all of the above observations on a composite map of the depth of $22^{\circ} \mathrm{C}$ isotherm $\left(Z_{22}\right)$, taken as a measure of the depth of the thermocline (see Fig. 2a), calculated from the 15-yr ARGO data from 1999 to 2014. At the SEATS mooring, $Z_{22} \approx 70-80 \mathrm{~m}$, while when it is deeper southwest of Taiwan, $Z_{22} \approx 110-130 \mathrm{~m}$, and $Z_{22} \approx 140 \mathrm{~m}$ when averaged over the ship track of Roemmich and Gilson (2001); the difference of $\delta Z_{22} \approx$ $30-70 \mathrm{~m}$ accounts for a large portion of $\delta z_{\max } \approx 50 \mathrm{~m}$ between the two sets of observations. Chen et al (2011) also found that, in SCS, the maximum temperature fluctuations due to eddies are near $z \sim-100 \mathrm{~m}$. In addition to the different thermocline depths, the SEATS mooring was also not always located near the eddy center, which also contributes to a shallower $z_{\max }$. On the other hand, the generally good agreements of $z_{\max }$ derived from the SVD analysis with other observations 

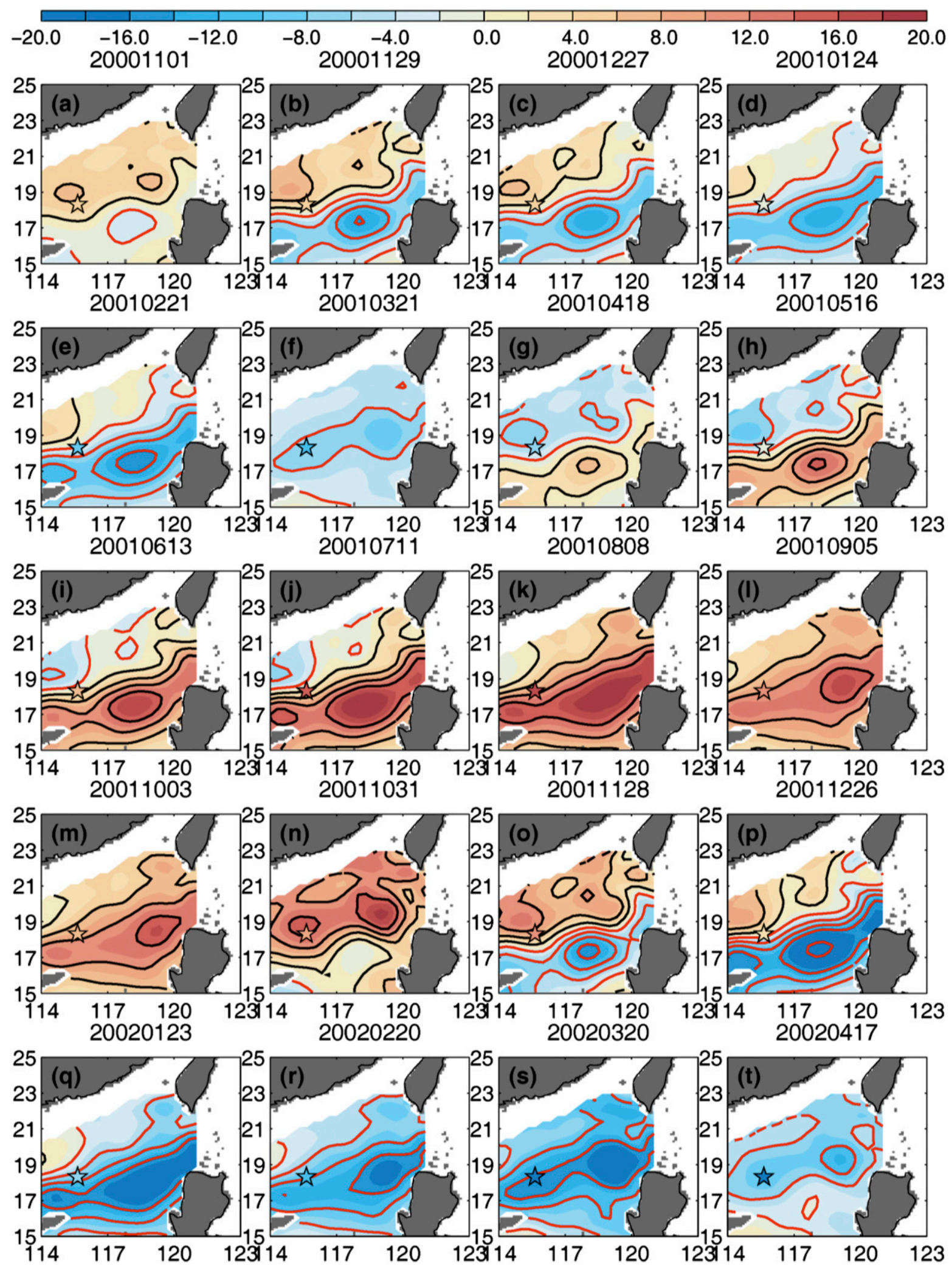

FIG. 7. Contribution of modes $1+2 \mathrm{ec}(\eta) \times \operatorname{sp}(\eta)$ of $\operatorname{SVD}(\eta, T)$ (shading $\pm 20 \mathrm{~cm}$ and black and red contours $= \pm 2, \pm 6, \pm 10, \pm 14$, and $\pm 22 \mathrm{~cm})$ every 4 weeks from 1 Nov 2000 through 17 April 2002. Star is SEATS colored according to modes $1+2\langle T\rangle$ of $\operatorname{SVD}(\eta,\langle T\rangle)$ at $z=$ $-300 \mathrm{~m}, \times 35\left[\approx(\partial T / \partial z)^{-1}\right]$ to give displacement in $\mathrm{m}$. The theoretical $y / x$ slope of phase lines estimated following White (1977) is approximately $2 / 3$ (note in the plot the $x$ axis is slightly more elongated). 

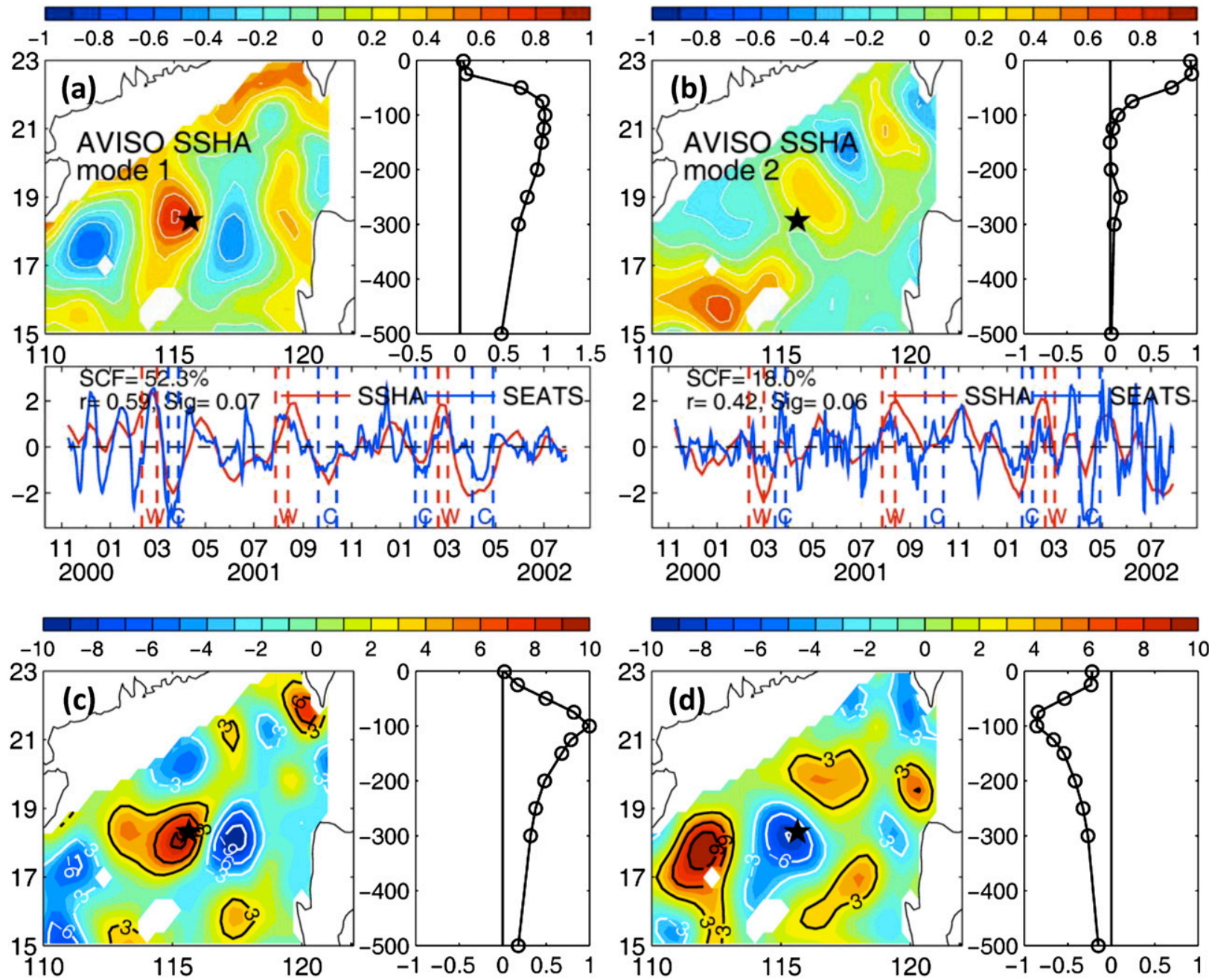

FIG. 8. SVD modes (a) 1 and (b) 2 of deseasoned SSHA with $T_{\text {eddy }}$. Upper subpanels show spatial patterns of SSHA (color shading and white contours) and SEATS $T$, and the lower subpanels show the ec, both normalized by their respective standard deviations. The star symbol shows the SEATS location. SCF is the square covariance fraction, $r$ is the correlation coefficient between the ec, and Sig is the $95 \%$ significance level. Composite of deseasoned SSHA [color shading black (positive) and white (negative) contours] and $T_{\text {eddy }}$ for all (c) warm and (d) cold eddies that passed within $75 \mathrm{~km}$ (three AVISO grids) of the SEATS mooring during the 22-month period. Vertical dashed lines in the lower subpanels of (a) and (b) indicate time periods when warm (W) and cold eddy (C) composites are made to plot panels (c) and (d).

(after accounting for the different thermocline depth) suggest that the SEATS location is indeed ideally located in the corridor of westward-propagating eddies in NSCS. By contrast, for eddies that propagate southwestward following the continental slope of the NSCS from southwest Taiwan (Caruso et al. 2006; Liang et al. 2008; Zhang et al. 2013), the SEATS mooring tends to be near the southern edges of the passing eddies as can be seen also by the $\operatorname{sp}_{2}\left(\eta-\eta_{a}\right)$ in Fig. $8 \mathrm{~b}$. The covarying signal is therefore weaker and the largest fluctuating temperature structure is biased near the surface.

The existence of $z_{\max } \approx-100 \mathrm{~m}$ from SVD analysis, where eddy-induced temperature fluctuations tend to be strongest, can be confirmed by directly compositing $\eta-\eta_{a}$ and $T_{\text {eddy }}$ for all eddies (i.e., regardless of patterns; southwestward or westward) whose centers came within $75 \mathrm{~km}$ (three AVISO grids) of the SEATS mooring. There were three warm eddies and four cold eddies, including one cold (see below; Figs. 9d-g) and one warm (Figs. 9c-h) eddy that were of the southwestwardpropagating type, and their composites are shown in Figs. $8 \mathrm{c}$ and $8 \mathrm{~d}$. The $z_{\max } \approx-100 \mathrm{~m}$ is clearly seen in the $T_{\text {eddy }}$ composites. On the other hand, while eddy patterns can be seen in the $\eta-\eta_{a}$ composites, unlike SVD, the composite method cannot sort out different patterns.

To illustrate the two patterns of eddies, Fig. 9 plots weekly $\eta$ in the winter of 2001/02. Here, a smoothed negative $\eta$ field first appears west of Luzon as the WSC 


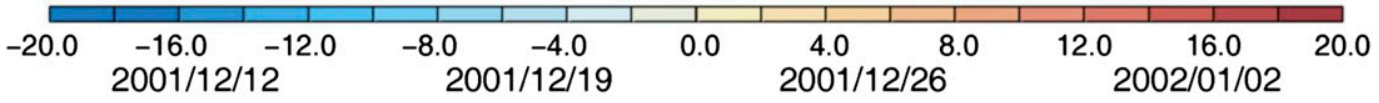
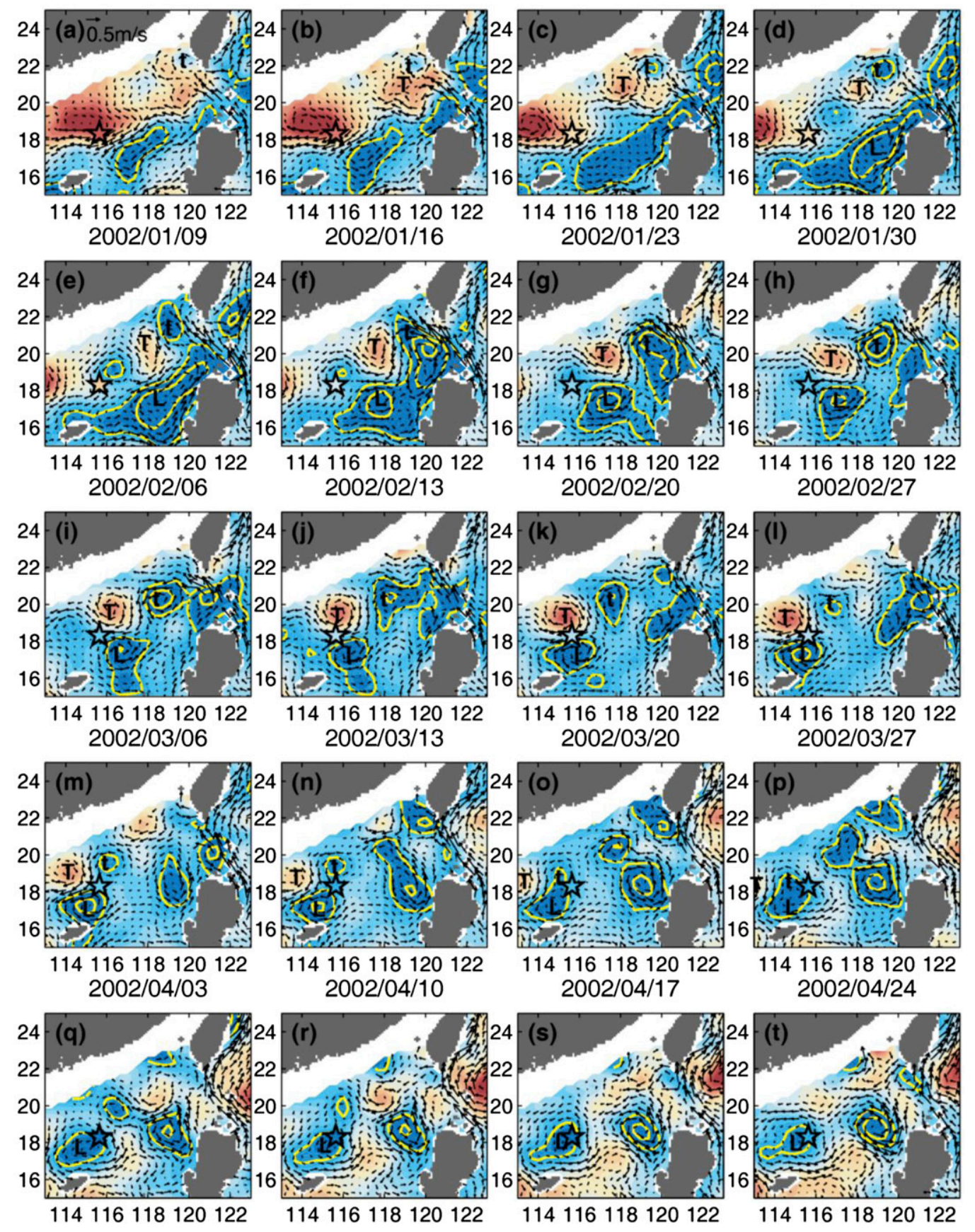

FIG. 9. Weekly AVISO SSHA (shading and yellow contours $=-14,-22$, and $-30 \mathrm{~cm}$ ) from 12 Dec 2001 to 24 Apr 2002 in NSCS $\left(15^{\circ}-25^{\circ} \mathrm{N}, 113^{\circ}-123^{\circ} \mathrm{E}\right)$. Vectors are geostrophic currents from AVISO SSH [scale shown in (a)]. Letters $\mathrm{T}$ (warm) and $\mathrm{t}$ (cold) denote Taiwan eddies, and L denotes Luzon eddy; see text. Star = SEATS station colored according to mode- $2 T$ of $\operatorname{SVD}(\mathrm{KP}, T)$ at $z=-100 \mathrm{~m}, \times 12\left[\approx(\partial T / \partial z)^{-1}\right]$ to give displacement in $\mathrm{m}$. Regions with water depths $<200 \mathrm{~m}$ have been masked. 
turns positive in fall and peaks in December (Figs. 9a-c). This is the initiation of westward spread of the (forced) Rossby wave according to the long-wave model equations (3.5)-(3.8), as described above by EOF1 +2 (Figs. 7o,p). A cyclonic eddy is then formed west of Luzon (Figs. 9d,e; eddy L) embedded in the westward spread and in due course the eddy detaches (Figs. 9f,g); the time scale for eddy detachment is $35-42$ days in good agreement with the above theoretical estimate. The eddy then propagates westward to the SEATS station (Figs. 9f-i) at an effective speed of about $5 \mathrm{~km}^{\text {day }}{ }^{-1}$, slightly slower than the Rossby wave speed $C_{R} \approx$ $0.06 \mathrm{~m} \mathrm{~s}^{-1}$ (cf. Matsuura and Yamagata 1982). The eddy is therefore seasonally locked to, and embedded within, the annual Rossby wave shown in Fig. 7. At the same time, the Kuroshio intrudes over the southwestern continental slope of Taiwan (Figs. 9a,b) and generates warm and cold eddies that can be traced southwestward to the SEATS station (Figs. 9c-h; eddies T and t).

\section{e. Connection with the Kuroshio}

To understand how Kuroshio fluctuations in the Luzon Strait covary with the SEATS temperature, Fig. 10 plots the leading modes 1 and 2 of $\operatorname{SVD}(\mathrm{KP}, T)$; these have SCFs $\approx 51 \%$ and $38 \%$, respectively, constituting $\sim 90 \%$ of the total covariance between KP and $T$. By comparing the mode- $1 \mathrm{sp}_{1}(T)$ and $\mathrm{ec}_{1}(T)$ of SVD $(\mathrm{KP}, T)$ in Fig. 10a with the mode- $1 \mathrm{sp}_{1}(\langle T\rangle)$ and $\mathrm{ec}_{1}(\langle T\rangle$ of $\operatorname{SVD}(\eta,\langle T\rangle)$ in Fig. 6a, it is clear that in mode 1, KP covaries predominantly with the annual fluctuation of SEATS temperature both near the surface and at subsurface below $z \approx-300 \mathrm{~m}$. The covarying $\operatorname{sp}_{1}(\mathrm{KP})$ (Fig. 10a) shows a structure of westward KP intrusion in the mid-Luzon Strait (stations 34-39) and eastward KP path south and north, and they generally occur in late summer to early winter when $\mathrm{ec}_{1}(\mathrm{KP})$ is positive. We will revisit this point below using the longer $\mathrm{KP}$ time series from 1993 to 2014. For mode 2 (Fig. 10b), ec $2(T)$ and $\operatorname{sp}_{2}(T)$ display strong fluctuations near $z \approx-100 \mathrm{~m}$, indicative of eddies. The $\mathrm{sp}_{2}(\mathrm{KP})$ is generally of one sign in the Luzon Strait (stations 30-41), and the sign of $\mathrm{ec}_{2}(\mathrm{KP})$ is generally positive (negative), so that KP is intrusive (eastward into the open Pacific), in fall and winter (spring and summer). Mode-2 KP therefore most effectively covaries with Kuroshio path fluctuations that generate eddies. To confirm this, we reconstruct time series of $\operatorname{ec}_{2}(T) \times \operatorname{sp}_{2}(T)$ of $\mathrm{SVD}(\mathrm{KP}, T)$ representing the eddy-induced temperature fluctuations at SEATS that most efficiently covary with KP as well as its highpassed version $\left[\mathrm{ec}_{2}(T)-\left\langle\mathrm{ec}_{2}(T)\right\rangle_{60 \mathrm{~d}}\right] \times \mathrm{sp}_{2}(T)$, shown in Fig. $10 \mathrm{c}$ as curves 2 and 3 , and correlate them with
$\mathrm{ec}_{1}\left(T_{\text {eddy }}\right) \times \operatorname{sp}_{1}\left(T_{\text {eddy }}\right)$ of $\operatorname{SVD}\left(\eta-\eta_{a}, T_{\text {eddy }}\right)$ from Fig. 8a (curve 1); they match well with high correlations. By comparing curves 1 and 2, we see that the latter shows shorter-period fluctuations embedded in an envelope of slower change. For the period shown in Fig. 9, from December 2001 to April 2002, the large westward KP excursion at station 39 in Fig. 10b in mid-December of 2001 can be clearly seen in Figs. 9a and 9b. As eddies pass the star (SEATS) location, Fig. 9 shows that the color of the star changes according to $\mathrm{ec}_{2}(T) \times \mathrm{sp}_{2}(T)$ of $\mathrm{SVD}(\mathrm{KP}, T)$ (curve 2 in Fig. 10c) in excellent agreement with the background color of SSHA from satellite data that show passages of eddies. By contrast, inspection of Fig. 10a shows that the slower-varying signal according to mode 1 of $\operatorname{SVD}(\mathrm{KP}, T)$ would not only be weaker at $z=-100 \mathrm{~m}$ but would also (incorrectly) indicate the same cold (i.e., blue) color throughout the period.

\section{Discussion}

Using a longer KP data (1993-2014), we find that EOF (KP) modes 1 and 2 account for $40 \%$ and $21 \%$ of the total variance (Fig. 11). These EOF modes are nearly identical to the KP modes of SVD(KP, T) in Fig. 10 but reversed. The SVD mode 2 of Fig. 10b becomes EOF mode 1 (Fig. 11a), and the SVD mode 1 (Fig. 10a) becomes the less dominant EOF mode 2 (Fig. 11b). Thus, the dominant KP fluctuation now has the simpler structure across the Luzon Strait, that is, the EOF $\mathrm{EV}_{1}(\mathrm{KP})$ is of one sign, similar to $\mathrm{sp}_{2}(\mathrm{KP})$ from stations $30-41$. The longer time series now yields a $\mathrm{PC}_{1}$ that has a clear annual variation: westward $\mathrm{KP}$ from OctoberApril with a maximum in February and eastward KP from April to September with a maximum in July. If westward KP path and intrusion are correlated, then these results are consistent with previous estimates of annual variation of throughflow transport in the Luzon Strait from hydrographic, model, and satellite data (Yaremchuk and Qu 2004; Qu et al. 2004; Chang and Oey 2012; Xu and Oey 2014, 2015; Zhang et al. 2015). The EOF $\mathrm{EV}_{2}(\mathrm{KP})$ structure is similar to $\mathrm{sp}_{1}(\mathrm{KP})$ (cf. Fig. 11b with Fig. 10a), and $\mathrm{PC}_{2}$ has both annual and semiannual variations. The annual variation shows generally westward KP in the middle of Luzon Strait (station 37) from October to January and eastward KP from February to September. The semiannual variation is caused by a near-zero KP in July. Thus, in the midLuzon Strait, the contribution of EOF1 to the westward (eastward) intrusion in winter (summer) is generally enhanced by EOF2, while it is diminished to the north and south. Therefore, westward (eastward) intrusion and cyclonic (anticyclonic) WSC both peak in winter (summer) and both contribute to the excitation of the 

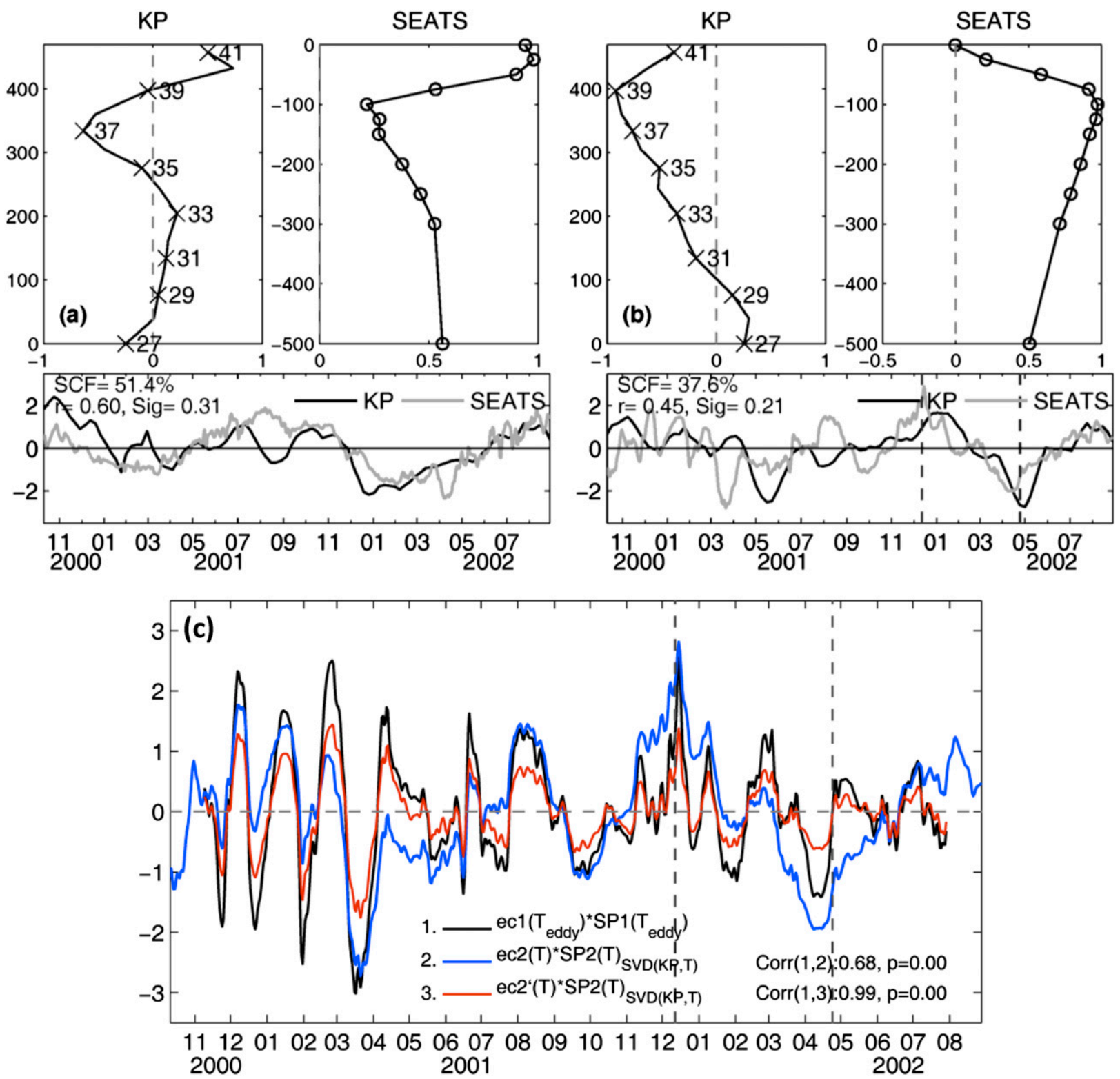

FIG. 10. SVD modes (a) 1 and (b) 2 of KP with SEATS $T$. Upper subpanels show sp of KP and SEATS $T$ and the lower subpanels show the corresponding expansion coefficients $\left(\mathrm{ec}_{1,2}\right)$, both normalized by their respective standard deviations. (c) Time series of 1 is ec $c_{1}\left(T_{\text {eddy }}\right) \times$ $\operatorname{sp}_{1}\left(T_{\text {eddy }}\right)$ of $\operatorname{SVD}\left(\eta-\eta_{a}, T_{\text {eddy }}\right)$ (i.e., from Fig. 8a), time series of 2 is $\operatorname{ec}_{2}(T) \times \operatorname{sp}_{2}(T)$ of $\operatorname{SVD}(\mathrm{KP}, T)$ [i.e., (b)], and time series of 3 is [ec $2(T)-$ $\left.\left\langle\mathrm{ec}_{2}(T)\right\rangle_{60 \mathrm{~d}}\right] \times \mathrm{sp}_{2}(T)$ of SVD(KP, T), all at $z=-100 \mathrm{~m}$; zero-lag correlations between 1 and 2 and between 1 and 3 , and their $p$ values are also displayed. The two vertical dashed lines in $\mathrm{ec}_{2}$ plot [i.e., right lower subpanel of (b)] and (c) indicate the period (12 Dec 2001 to 24 Apr 2002 ) of the weekly plots shown in Fig. 6. Sig is the 95\% significance level for $r$.

annual Rossby wave as has been previously demonstrated by $\mathrm{Xu}$ and Oey (2015) [see (3.7)]. It is more difficult, however, to separate from observations the effects of WSC and KP on eddies and eddy production. Medium and larger cyclones (diameters $>\sim 100 \mathrm{~km}$ ) could be spun up by WSC west of Luzon, while smaller eddies were found southwest of Taiwan (Qu 2000; Wang et al. 2003, 2008; Caruso et al. 2006; Liang et al. 2008; Li et al. 2011). On the other hand, Nan et al. (2011, their
Fig. 3; 2014) questioned that eddies were WSC driven, since they found only a weak correlation between WSC and eddy occurrence. The authors argued instead that KP fluctuations would be more effective in generating eddies. Our analyses during the SEATS period indicate that southwestward-propagating eddies were produced southwest of Taiwan due to Kuroshio intrusion, while eddies were spun up northwest of Luzon by WSC, embedded in Rossby waves. Indeed, this view is not inconsistent 

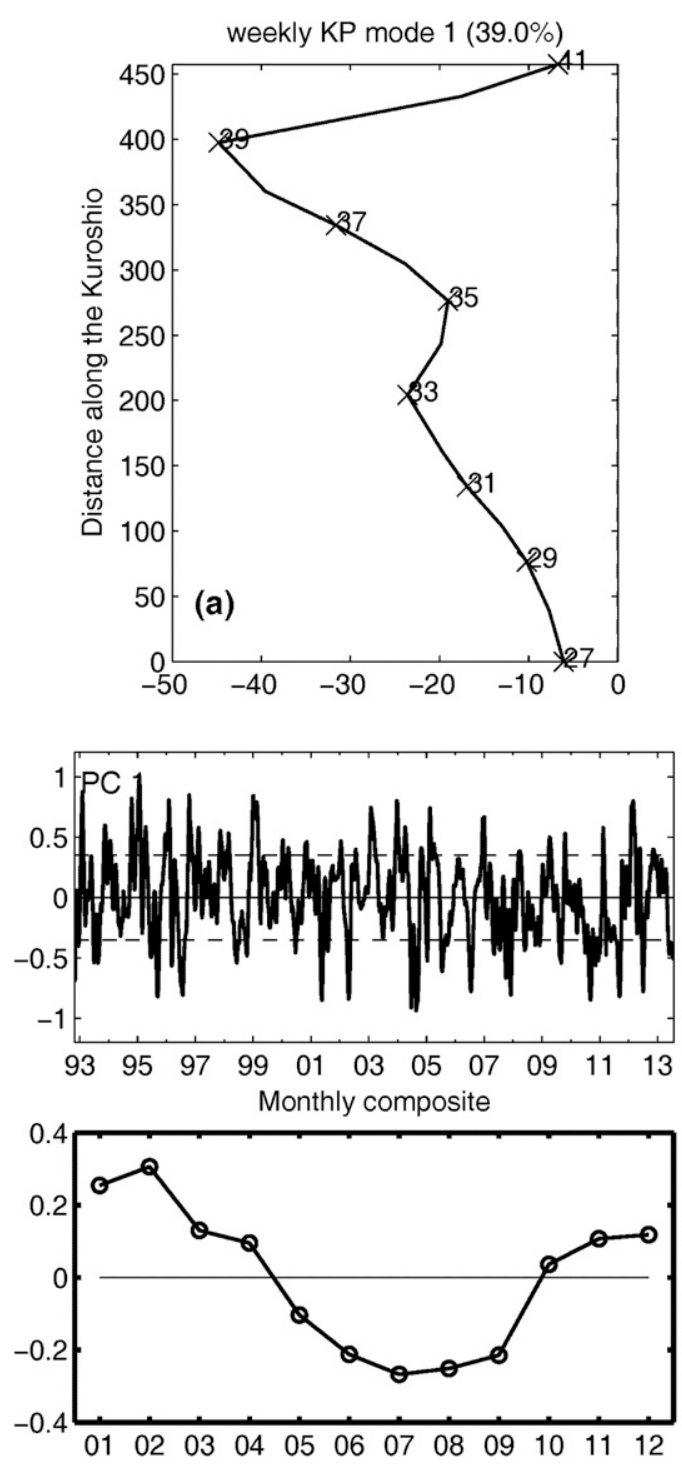
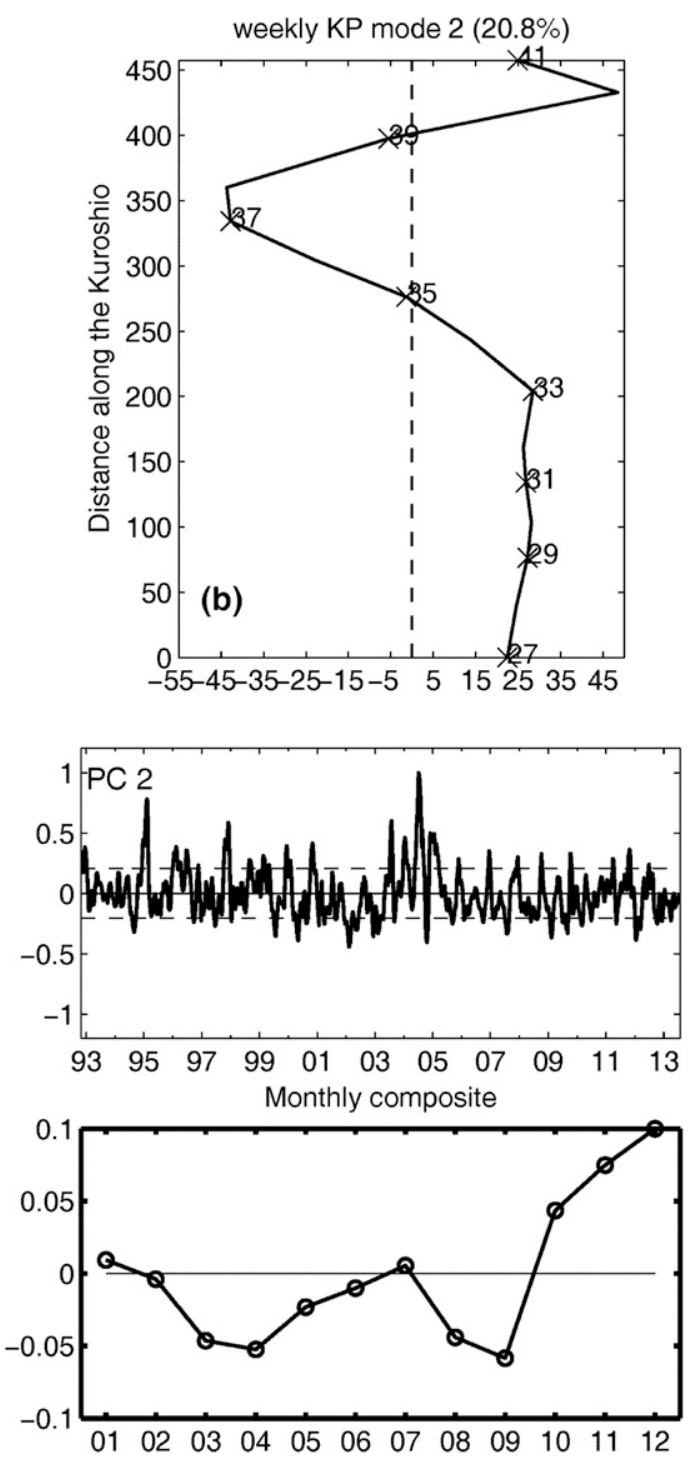

FIG. 11. Modes (left) 1 and (right) 2 of EOF(KP) showing (top) EV in Luzon Strait: stations 30-41 (see Fig. 1b for station locations) and (middle) weekly PCs (dashed lines are plus or minus one standard deviation) from 1993 to 2014 and (bottom) their monthly composites January-December.

with the eddy occurrence plot in Fig. 3 of Nan et al. (2011). There, winter eddy occurrence was low west of Luzon, since this was a period when the smooth spreading of the Rossby wave began, but eddy occurrence became high in spring farther to the west (see their Fig. 3a), where eddies then arrived (cf. Fig. 9). Model experiments may be conducted in the future to attempt isolating these different processes.

\section{Conclusions}

The 22-month temperature observations at a station $\sim 450 \mathrm{~km}$ due west of Luzon at $\sim 18^{\circ} \mathrm{N}$ in NSCS are analyzed with satellite and other supporting data using
EOF and SVD methods to describe westward-propagating annual Rossby waves and mesoscale eddies. The major findings are as follows:

1) Annual temperature fluctuations are strongest at mooring depths deeper than $z \approx-300 \mathrm{~m}$.

2) The deep fluctuations are caused by arrivals of westward- and downward-propagating, energetic, annual Rossby waves excited near the surface off Luzon by annual fluctuations of WSC and Kuroshio path.

3) The group (phase) speed of the observed Rossby wave, $0.1-0.12 \mathrm{~m} \mathrm{~s}^{-1}$, is approximately twice the theoretical phase speed of Rossby wave of $\sim 0.06 \mathrm{~m} \mathrm{~s}^{-1}$. 
4) The SVD analysis of covariability between temperature at the mooring and satellite altimetry SSHA data in NSCS yields two types of mesoscale eddy patterns around the mooring: westward originating from Luzon and southwestward originating from southwestern Taiwan.

5) Mesoscale eddies are embedded in the annual Rossby waves and produce strong subsurface temperature fluctuations just below the thermocline at $z \approx-100 \mathrm{~m}$.

6) The cyclone observed in winter during the SEATS period is forced by WSC in agreement with previous findings; the eddy translates westward at a speed that is slightly less than the theoretical Rossby wave phase speed.

7) The dominant mode of Kuroshio path fluctuations in Luzon Strait consist of westward intrusion in fall and winter and eastward meander anomalies in spring and summer, and the path fluctuations covary with temperature fluctuations at SEATS that are at maximum near $z \approx-100 \mathrm{~m}$, indicative of eddies in NSCS.

With regard to the last point, the present study does not separate the contributions of WSC and Kuroshio path fluctuations to eddy variability and Rossby waves in NSCS. It will be an interesting future study to visit the topic using models.

Acknowledgments. Dr. Yih Yang of TORI provided the SEATS data and Dr. Jia Wang (NCU) provided the code to compute KP. LYO is grateful for the award he received from the Taiwan's Foundation for the Advancement of Outstanding Scholarship. The research was in part supported by the National Science Council, the Ministry of Education, and the National Central University, Taiwan.

\section{REFERENCES}

Antonov, J. I., R. A. Locarnini, T. P. Boyer, A. V. Mishonov, and H. E. Garcia, 2006: Salinity. Vol. 2, World Ocean Atlas 2005 , NOAA Atlas NESDIS 62, $182 \mathrm{pp}$.

Atlas, R., R. N. Hoffman, J. Ardizzone, M. Leidner, and J. C. Jusem, 2009: Development of a new cross-calibrated, multi-platform (CCMP) ocean surface wind product. 13th Conf. on Integrated Observing and Assimilation Systems for Atmosphere, Oceans, and Land Surface (IOAS-AOLS), Phoenix, AZ, Amer. Meteor. Soc., 4B.1. [Available online at https://ams.confex.com/ ams/89annual/techprogram/paper_145957.htm.]

AVISO, 2013: MDT_CNES-CLS13. CLS Space Oceanography Division with support from CNES, accessed 6 December 2014. [Available online at http://www.aviso.altimetry.fr/.]

Bretherton, C. S., C. Smith, and J. M. Wallace, 1992: An intercomparison of methods for finding coupled patterns in climate data. J. Climate, 5, 541-560, doi:10.1175/ 1520-0442(1992)005<0541:AIOMFF > 2.0.CO;2.

Caruso, M., G. G. Gawarkiewicz, and R. Beardsley, 2006: Interannual variability of the Kuroshio Current intrusion in the
South China Sea. J. Oceanogr., 62, 559-575, doi:10.1007/ s10872-006-0076-0.

Chang, P., L. Ji, and H. Li, 1997: A decadal climate variation in the tropical Atlantic Ocean from thermodynamic air-sea interactions. Nature, 385, 516-518, doi:10.1038/385516a0.

Chang, Y.-L., and L.-Y. Oey, 2012: The Philippines-Taiwan Oscillation: Monsoonlike interannual oscillation of the subtropical-tropical western North Pacific wind system and its impact on the ocean. J. Climate, 25, 1597-1618, doi:10.1175/JCLI-D-11-00158.1.

, and -2013 : Coupled response of the trade wind, SST gradient, and SST in the Caribbean Sea, and the potential impact on loop current's interannual variability. J. Phys. Oceanogr., 43, 1325-1344, doi:10.1175/JPO-D-12-0183.1.

Chelton, D. B., M. G. Schlax, and R. M. Samelson, 2011: Global observations of nonlinear mesoscale eddies. Prog. Oceanogr., 91, 167-216, doi:10.1016/j.pocean.2011.01.002.

Chen, G. X., Y. Hou, X. Chu, and P. Qi, 2010: Vertical structure and evolution of the Luzon warm eddy. Chin. J. Oceanol. Limnol., 28, 955-961, doi:10.1007/s00343-010-9040-3.

,$- \ldots$, and -2011 : Mesoscale eddies in the South China Sea: Mean properties, spatiotemporal variability and impact on thermohaline structure. J. Geophys. Res., 116, C06018, doi:10.1029/2010JC006716.

Chu, P. C., C. W. Fan, C. J. Lozano, and J. L. Kerling, 1998: An airborne expendable bathythermograph survey of the South China Sea, May 1995. J. Geophys. Res., 103, 21 637-21 652, doi:10.1029/98JC02096.

Fang, G., W. Fang, Y. Fang, and K. Wang, 1998: A survey of studies on the South China Sea upper ocean circulation. Acta Oceanogr. Taiwanica, 37, 1-16.

Gan, J., H. Li, E. N. Curchitser, and D. B. Haidvogel, 2006: Modeling South China Sea circulation: Response to seasonal forcing regimes. J. Geophys. Res., 111, C06034, doi:10.1029/2005JC003298.

Gill, A. E., 1982: Atmosphere-Ocean Dynamics. Academic Press, $662 \mathrm{pp}$.

Hu, J., Q. Zheng, Z. Sun, and C. K. Tai, 2012: Penetration of nonlinear Rossby eddies into South China Sea evidenced by cruise data. J. Geophys. Res., 117, C03010, doi:10.1029/2011JC007525.

Huang, N. E., and Coauthors, 1998: The empirical mode decomposition and the Hilbert spectrum for nonlinear and nonstationary time series analysis. Proc. Roy. Soc. London, A454, 903-995, doi:10.1098/rspa.1998.0193.

Kessler, W. S., and J. P. McCreary, 1993: The annual wind-driven Rossby wave in the subthermocline equatorial Pacific. J. Phys. Oceanogr., 23, 1192-1207, doi:10.1175/1520-0485(1993)023<1192: TAWDRW $>2.0 . \mathrm{CO} ; 2$.

Kundu, P., J. S. Allen, and R. L. Smith, 1975: Modal decomposition of the velocity field near the Oregon coast. J. Phys. Oceanogr., 5, 683-704, doi:10.1175/1520-0485(1975)005<0683: MDOTVF>2.0.CO;2.

Kutzbach, J. E., 1967: Empirical eigenvectors of sea-level pressure, surface temperature, and precipitation complexes over North America. J. Appl. Meteor., 6, 791-802, doi:10.1175/ 1520-0450(1967)006<0791:EEOSLP $>2.0 . C O ; 2$.

Li, J., R. Zhang, and B. Jin, 2011: Eddy characteristics in the northern South China Sea as inferred from Lagrangian drifter data. Ocean Sci., 7, 661-669, doi:10.5194/os-7-661-2011.

Liang, W.-D., Y. J. Yang, T. Y. Tang, and W.-S. Chuang, 2008: Kuroshio in the Luzon Strait. J. Geophys. Res., 113, C08048, doi:10.1029/2007JC004609.

Lin, X., L.-Y. Oey, and D.-P. Wang, 2007: Altimetry and drifter assimilations of Loop Current and eddies. J. Geophys. Res., 112, C05046, doi:10.1029/2006JC003779. 
Liu, Z., H. Yang, and Q. Liu, 2001: Regional dynamics of seasonal variability in the South China Sea. J. Phys. Oceanogr., 31, 272284, doi:10.1175/1520-0485(2001)031<0272:RDOSVI >2.0.CO;2.

Locarnini, R. A., A. V. Mishonov, J. I. Antonov, T. P. Boyer, and H. E. Garcia, 2006: Temperature. Vol. 1, World Ocean Atlas 2005, NOAA Atlas NESDIS 61, 182 pp.

Lu, J., and Q. Liu, 2013: Gap-leaping Kuroshio and blocking westward-propagating Rossby wave and eddy in the Luzon Strait. J. Geophys. Res. Oceans, 118, 1170-1181, doi:10.1002/ jgrc.20116.

Matsuura, T., and T. Yamagata, 1982: On the evolution of nonlinear planetary eddies larger than the radius of deformation. J. Phys. Oceanogr., 12, 440-456, doi:10.1175/ 1520-0485(1982)012<0440:OTEONP > 2.0.CO;2.

Mellor, G. L., 2001: One-dimensional, ocean surface layer modeling: A problem and a solution. J. Phys. Oceanogr., 31, 790-809, doi:10.1175/1520-0485(2001)031<0790:ODOSLM >2.0.CO;2.

Merrifield, M. A., and R. T. Guza, 1990: Detecting propagating signals with complex empirical orthogonal functions: A cautionary note. J. Phys. Oceanogr., 20, 1628-1633, doi:10.1175/ 1520-0485(1990)020<1628:DPSWCE $>2.0 . C O ; 2$.

Metzger, E. J., 2003: Upper ocean sensitivity to wind forcing in the South China Sea.J. Oceanogr., 59, 783-798, doi:10.1023/ B:JOCE.0000009570.41358.c5.

Nan, F., H. Xue, P. Xiu, F. Chai, M. Shi, and P. Guo, 2011: Oceanic eddy formation and propagation southwest of Taiwan. J. Geophys. Res., 116, C12045, doi:10.1029/2011JC007386.

, and F. Yu, 2014: Kuroshio intrusion into the South China Sea: A review. Prog. Oceanogr., 137, 314-333, doi:10.1016/ j.pocean.2014.05.012.

Newman, M., and P. D. Sardeshmukh, 1995: A caveat concerning singular value decomposition. J. Climate, 8, 352-360, doi:10.1175/ 1520-0442(1995)008<0352:ACCSVD > 2.0.CO;2.

Oey, L.-Y., 2008: Loop Current and deep eddies. J. Phys. Oceanogr., 38, 1426-1449, doi:10.1175/2007JPO3818.1.

- H.-C. Lee, and W. J. Schmitz, Jr., 2003: Effects of winds and Caribbean eddies on the frequency of Loop Current eddy shedding: A numerical model study. J. Geophys. Res., 108, 3324, doi:10.1029/2002JC001698.

- M. Inoue, R. Lai, X.-H. Lin, S. E. Welsh, and L. J. Rouse Jr., 2008: Stalling of near-inertial waves in a cyclone. Geophys. Res. Lett., 35, L12604, doi:10.1029/2008GL034273.

—, Y.-L. Chang, Z.-B. Sun, and X.-H. Lin, 2009: Topocaustics. Ocean Modell., 29, 277-286, doi:10.1016/j.ocemod.2009.05.006.

, R. Chang, S.-M. Huang, Y.-C. Lin, and M.-A. Lee, 2015: The influence of shelf-sea fronts on winter monsoon over East China Sea. Climate Dyn., 45, 2047-2068, doi:10.1007/ s00382-014-2455-3.

Qu, T., 2000: Upper layer circulation in the South China Sea. J. Phys. Oceanogr., 30, 1450-1460, doi:10.1175/ 1520-0485(2000)030<1450:ULCITS > 2.0.CO;2.

—, Y. Y. Kim, M. Yaremchuk, T. Tozuka, A. Ishida, and T. Yamagata, 2004: Can Luzon Strait transport play a role in conveying the impact of ENSO to the South China Sea? J. Climate, 17, 3644-3657, doi:10.1175/1520-0442(2004)017<3644: CLSTPA $>2.0 . \mathrm{CO} ; 2$.

Ramos, M., B. Dewitte, O. Pizarro, and G. Garric, 2008: Vertical propagation of the extratropical Rossby wave during the 1997-1998 El Niño off the west coast of South America in a medium-resolution OGCM simulation. J. Geophys. Res., 113, C08041, doi:10.1029/2007JC004681.

Rio, M. H., S. Guinehut, and G. Larnicol, 2011: New CNES-CLS09 global mean dynamic topography computed from the combination of GRACE data, altimetry, and in situ measurements. J. Geophys. Res., 116, C07018, doi:10.1029/2010JC006505.

Roemmich, D., and J. Gilson, 2001: Eddy transport of heat and thermocline waters in the North Pacific: A key to interannual/ decadal climate variability? J. Phys. Oceanogr., 31, 675-687, doi:10.1175/1520-0485(2001)031<0675:ETOHAT>2.0.CO;2.

Samelson, R. M., 1992: Fluid exchange across a meandering jet. J. Phys. Oceanogr., 22, 431-440, doi:10.1175/1520-0485(1992)022<0431 FEAAMJ $>2.0 . \mathrm{CO} ; 2$

Sheu, W.-J., C.-R. Wu, and L.-Y. Oey, 2010: Blocking and westward passage of eddies in the Luzon Strait. Deep-Sea Res. II, 57, 1783-1791, doi:10.1016/j.dsr2.2010.04.004.

Smith, D. C., and J. J. O'Brien, 1983: The interaction of a two-layer isolated mesoscale eddy with bottom topography. J. Phys. Oceanogr., 13, 1681-1697, doi:10.1175/1520-0485(1983)013<1681: TIOATL $>2.0 . C O ; 2$.

Sun, J., L.-Y. Oey, R. Chang, F.-H. Xu, and S.-M. Huang, 2015: Ocean response to Typhoon Nuri (2008) in western Pacific and South China Sea. Ocean Dyn., 65, 735-749, doi:10.1007/ s10236-015-0823-0.

Venegas, S. A., L. A. Mysak, and D. N. Straub, 1996: Evidence for interannual and interdecadal climate variability in the South Atlantic. Geophys. Res. Lett., 23, 2673-2676, doi:10.1029/ 96GL02373.

_ - , and — 1997: Atmosphere-ocean coupled variability in the South Atlantic. J. Climate, 10, 2904-2920, doi:10.1175 1520-0442(1997)010<2904:AOCVIT>2.0.CO;2.

von Storch, H., and A. Navarra, Eds., 1995: Analysis of Climate Variability. Springer, $342 \mathrm{pp}$.

Wallace, J. M., C. Smith, and C. S. Bretherton, 1992: Singular value decomposition of wintertime sea-surface temperature and 500-mb height anomalies. J. Climate, 5, 561-576, doi:10.1175/ 1520-0442(1992)005<0561:SVDOWS $>2.0 . \mathrm{CO} ; 2$

Wang, G., J. Su, and P. C. Chu, 2003: Mesoscale eddies in the South China Sea observed with altimeter data. Geophys. Res. Lett., 30, 2121, doi:10.1029/2003GL018532.

- D. Chen, and J. L. Su, 2008: Winter eddy genesis in the eastern South China Sea due to orographic wind jets. J. Phys. Oceanogr., 38, 726-732, doi:10.1175/2007JPO3868.1.

— , J. Li, C. Wang, and Y. Yan, 2012: Interactions among the winter monsoon, ocean eddy and ocean thermal front in the South China Sea. J. Geophys. Res., 117, C08002, doi:10.1029/ 2012JC008007.

Wang, J., and L.-Y. Oey, 2014: Inter-annual and decadal fluctuations of the Kuroshio in East China Sea and connection with surface fluxes of momentum and heat. Geophys. Res. Lett., 41, 8538-8546, doi:10.1002/2014GL062118.

White, B. W., 1977: Annual forcing of baroclinic long waves in the tropical North Pacific Ocean. J. Phys. Oceanogr., 7, 50-61, doi:10.1175/1520-0485(1977)007<0050:AFOBLW>2.0.CO;2.

Wong, G. T. F., T.-L. Ku, M. Mulholland, C.-M. Tseng, and D.-P Wang, 2007: The SouthEast Asian Time-Series Study (SEATS) and the biogeochemistry of the South China SeaAn overview. Deep-Sea Res. II, 54, 1434-1447, doi:10.1016/ j.dsr2.2007.05.012.

Wyrtki, K., 1961: Physical Oceanography of the Southeast Asian Waters. NAGA Rep., Vol. 2, Scripps Institute of Oceanography, 195 pp.

Xu, F.-H., and L.-Y. Oey, 2014: State analysis using the local ensemble transform Kalman filter (LETKF) and the threelayer circulation structure of the Luzon Strait and the South China Sea. Ocean Dyn., 64, 905-932, doi:10.1007/ s10236-014-0720-y. 
— , and — 2015: Seasonal SSH variability of the northern South China Sea. J. Phys. Oceanogr., 45, 1595-1609, doi:10.1175/ JPO-D-14-0193.1.

Xue, H., F. Chai, N. Pettigrew, D. Xu, M. Shi, and J. Xu, 2004: Kuroshio intrusion and the circulation in the South China Sea. J. Geophys. Res., 109, C02017, doi:10.1029/2002JC001724.

Yang, H., and Q. Liu, 2003: Forced Rossby wave in the northern South China Sea. Deep-Sea Res. I, 50, 917-926, doi:10.1016/ S0967-0637(03)00074-8.
Yaremchuk, M., and T. Qu, 2004: Seasonal variability of the large-scale currents near the coast of Philippines. J. Phys. Oceanogr., 34, 844 855, doi:10.1175/1520-0485(2004)034<0844:SVOTLC $>2.0$. CO;2.

Zhang, Z., W. Zhao, J. Tian, and X. Liang, 2013: A mesoscale eddy pair southwest of Taiwan and its influence on deep circulation. J. Geophys. Res., 118, 6479-6494, doi:10.1002/2013JC008994.

, - - _ - Q. Yang, and T. Qu, 2015: Spatial structure and temporal variability of the zonal flow in the Luzon Strait. J. Geophys. Res. Oceans, 120, 759-776, doi:10.1002/2014JC010308. 